\title{
Ash Behaviour during Combustion of Agropellets Produced by an Agro-Industry-Part 1: Blends Design and Experimental Tests Results
}

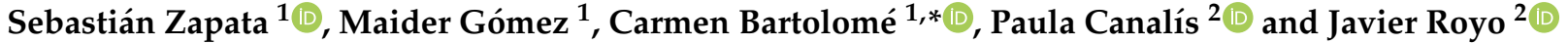 \\ 1 CIRCE Foundation, Parque Empresarial Dinamiza, 50018 Zaragoza, Spain; szapata@fcirce.es (S.Z.); \\ mgomez@fcirce.es (M.G.) \\ 2 CIRCE Institute, University of Zaragoza, 50018 Zaragoza, Spain; pmcanmar@unizar.es (P.C.); \\ fjroyo@unizar.es (J.R.) \\ * Correspondence: cbartolome@fcirce.es
}

Citation: Zapata, S.; Gómez, M.; Bartolomé, C.; Canalís, P.; Royo, J.

Ash Behaviour during Combustion of Agropellets Produced by an Agro-Industry-Part 1: Blends Design and Experimental Tests Results. Energies 2022, 15, 1479.

https://doi.org/10.3390/en15041479

Academic Editors: Ilona

Sárvári Horváth

Cigdem Yangin-Gomec and

Carlos Martín

Received: 28 December 2021

Accepted: 9 February 2022

Published: 17 February 2022

Publisher's Note: MDPI stays neutral with regard to jurisdictional claims in published maps and institutional affiliations.

Copyright: (C) 2022 by the authors. Licensee MDPI, Basel, Switzerland. This article is an open access article distributed under the terms and conditions of the Creative Commons Attribution (CC BY) license (https:// creativecommons.org/licenses/by/ $4.0 /)$.

\begin{abstract}
Agropellets are presented as a suitable product to be produced in certain agro-industries which could become Integrated Biomass Logistic Centres (IBLC) by taking advantage of its current resources during those periods in which their facilities are underused. Wheat straw and maize stalk were selected to be blended with forestry wood in an agro-industry dedicated to animal feed production. The materials were characterized to assess the quality of the input material. Taking into account the former, different pellets (blends of woody and herbaceous biomass) were produced and tested in a fixed bed reactor in order to study their combustion behaviour. Additionally, several predictive indexes were also calculated to assess sintering and deposition occurrence probability. Ash sintering degree was found to be directly related to composition and highly dependent on Si content. Moreover, an increase of the wood content in the blend did not proportionally imply a higher quality of the final blend, as would be expected. Regarding deposition, due to the high number of factors involved in this phenomenon, it has not been possible to draw clear conclusions. To do this, it was necessary to delve into the deposition mechanisms, which is addressed in the second part of this paper. Thus, despite the appearance of sintering and deposition phenomena, the combustion behaviour was satisfactory in the test carried out. Additionally, it has been demonstrated that agro-industries can act as IBLCs, producing blended pellet for the energy market that aligns with the standard ISO 17225-6.
\end{abstract}

Keywords: integrated biomass logistic centre; agro-industry; combustion; agropellets; fixed bed reactor; bottom ash sintering; deposition

\section{Introduction}

Nowadays, agro-industries are facing several barriers that hinder their competitiveness, such as their seasonal nature which implies long or even non-existing activity periods, and the underutilization of opportunities, such as the exploitation of their own residues or those from nearby areas in order to create a new business line. In this context, AGROinLOG project [1] focuses on their transformation into Integrated Biomass Logistic Centres (IBLC). This concept has been analysed in several European projects, such as Europrunning [2], SUCELLOG [3,4], BioRES [5], or Vineyard for heat [6].

Among the demo sites developed in AGROinLOG project, this paper presents results from a fodder industry in which agropellets were produced. The reason why agropellets were selected as a suitable product was the growing demand of different sources of biomass worldwide [7]. This increasing demand is partially due to the new uses for forest biomass [8] which makes it necessary to test new biofuels. Their production took place during the fodder industry "low activity period", taking advantage of their contact network and a low investment required due to the already available means (machinery, staff, etc.). This way, 
the fodder company was transformed into an IBLC, and the feasibility of this concept was assessed during the project.

Regarding the agropellet production, the first step dealt with the selection of the most suitable raw materials. Different herbaceous materials from the surrounding areas were considered and some of them were selected as raw material for the pellet manufacturing.

Regarding the combustion characteristics of herbaceous biomass, it is important to highlight their high ash content with a significant concentration of alkalis and/or chlorine [9], which may derive in some cases into deposition and corrosion problems. The ash can be divided into the components remaining as solid fraction and those which are volatilized [10]. In any case, both parts have to be taken into account when analysing the combustion performance of a new biofuel. The characteristics of the solid fraction affecting conversion in the bed may cause sintering in the grate, thus worsening efficiency and emissions. Regarding volatilization mechanisms, these mainly are related to alkalis, since they are responsible for corrosion and erosion of heat transfer surfaces. Due to their important consequences and complexity, numerous works have been published addressing this topic [11-13].

For this reason, from the beginning, it was considered necessary to do some research about the design and production criteria of blended pellets, and not just produce pellets $100 \%$ made with herbaceous material. Forestry wood was considered as a complementary material to be blended with herbaceous biomass, aiming to obtain a biofuel with better combustion characteristics. These materials will be widely described in Section 2 .

The present research consisted of a complete experimental analysis regarding the feasibility to achieve an efficient combustion of agropellets produced in a IBCL in grate boiler technology. In order to achieve this objective, and due to the complete work extension, it was divided into two different papers: the first one which, in addition to the description of the fuel production and a discussion of their final characteristics, includes the combustion performance analysis by means of an extensive experimental work; and the second one, which focused on an extensive sintering and deposition study, including different analytical techniques for its evaluation (SEM-EDS and XRD). The ultimate goal is to assess barriers and opportunities in-depth to efficiently burn the selected agropellets in a grate boiler for energy purposes.

\section{Materials and Methods}

\subsection{Fuels}

\subsubsection{Definition of Blends}

As it was previously stated, an extensive study was carried out to determine the most suitable materials to be analysed in this research work. The starting point of the analysis was to evaluate the available residual agricultural biomass from the surrounding area where the IBLC is located. This is the reason why wheat straw and maize stalk were selected to develop blended pellets, together with forestry wood. As the work progressed, these blended pellets were classified in two families (henceforth, the acronym WSP refers to the wheat straw pellet family and MSP refers to the maize stalk pellet family).

The straw and maize stalk raw materials were initially analysed to determine the amount of wood required in the blend to fulfil the ISO 17225-6 [14] standard for non-woody pellets. Based on this preliminary information, $55 \%$ and $75 \%$ wood would need to be added to the blend with wheat straw and maize stalk, respectively, to comply with the Class B of the quality standard mentioned due to the high content of ash and chlorine in these herbaceous materials, as they turned out to be the most limiting parameters as already proven in other studies [10]. A higher amount of wood in the blend involves a higher cost associated both to the costs of raw material and the drying and milling process required. Blended pellets will not only need to fulfil quality requirements, but also economic profitability criteria. Therefore, in order to decrease the amount of wood blended, a traceability assessment was performed to select the location from which the most suitable raw material for energy uses could be collected, since the chlorine content (and other 
elements) has a huge variability associated to the area where these crops are cultivated, as well as other parameters like the management of the crop or climate conditions.

For this aim, the first step included the identification of the main suppliers of the agro-industry and mapping of their corresponding collecting areas. Secondly, the total supply area was divided in nine subareas according to their characteristics, and samples were taken and analysed to determine the average quality of the herbaceous material (proximate analysis, ultimate analysis, and ash composition were performed). A sampling protocol was designed in order to collect representative samples of the material stored by the main suppliers of the agro-industry.

Based on this traceability study, two areas were found in which wheat straw had a lower ash and chlorine content, low enough to even allow to avoid adding wood in the blend while fulfilling ISO $17225-6$, class B. It should be noted that in principle $55 \%$ of wood should be added in order to fulfil with this standard. Regarding maize stalk, one area was selected to develop the blends, but in this case the results were not as good as the ones obtained with wheat straw.

Once the traceability study was done, the next step dealt with the design of the blend, seeking to fulfil the quality standards (ISO-17225-6 class A and B) while achieving a market competitive product. Therefore, the blend composition was determined considering:

1. $100 \%$ woody and herbaceous biofuels were used to determine the range of the operational costs and to evaluate their behaviour in the laboratory set-up.

2. Blend pellets should satisfy ISO-17225-6 class A and B (see Table 1). At least two blends of straw and two of stalk were designed to satisfy some of these classes requirements, being the main parameters considered to fulfil with the standard indicated in the Table 1 .

Table 1. Properties of non-woody pellets (mixed pellets included) according to ISO $17225-6$ (\% a.r.: weight percentage as received; \% d.b.: weight percentage in dry basis).

\begin{tabular}{lcc}
\hline \multicolumn{1}{c}{ Property } & Class A & Class B \\
\hline Moisture content (\% a.r.) & $\leq 12$ & $\leq 15$ \\
Ash content (\% d.b.) & $\leq 6$ & $\leq 10$ \\
Low heating value (kWh/kg a.r.) & $\geq 4.0$ & $\geq 4.0$ \\
$\mathrm{Cl}(\%$ d.b.) & $\leq 0.10$ & $\leq 0.30$ \\
\hline
\end{tabular}

1. To satisfy economic criteria looking for a currently competitive blend in the biomass market near of the agro-industry facility [15]. The main competitors of the blended pellet produced are, for example, industrial forestry pellets, the selling price of which in the near market of the agro-industry is around $170 € / \mathrm{t}_{\mathrm{wb}}$, forestry wood chip $\left(85 € / t_{\mathrm{wb}}\right)$, olive pits $(120 € / \mathrm{twb})$, among others.

2. The blends were produced gradually, taking into account the criteria previously mentioned and the results achieved during the combustion performance tests in the fixed bed reactor. Firstly, the pure herbaceous fuels were produced (WSP100, MSP100, and WP100) and tested in the reactor, and then one blend based on straw and stalk was produced and tested. Table 2 shows from the left to the right the production order followed for each fuel family.

Regarding the durability and bulk density, the values obtained were lower than expected in some cases, which is mainly due to the lack of experience of the IBLC working with blends pellets. This characteristic can be improved by selecting a more adequate blend for the pelletizing process.

Based on these results and considering the design criteria assessed, the WSP100 complies with ISO 17225-6 class B and has a competitive price considering current prices of the biomass market in the region. On the other hand, the MSP100 did not satisfy the quality ISO standard and therefore it is not suitable for the targeted market. WP100 fulfilled class A criteria as expected. Regarding the blended pellets, the MSP52 blend only met class B 
criteria and was not very competitive due to its selling price being under current market conditions. The WSP35 and MSP10 comply with class A ISO 17225-6 criteria, but again were not currently very competitive in the local market. Finally, the WSP60 and WSP72 wood blends reached class A criteria and were competitive in the local market.

Table 2. Fuel properties (\% a.r.: weight percentage as received; \% d.b.: weight percentage in dry basis).

\begin{tabular}{|c|c|c|c|c|c|c|c|c|c|}
\hline & & WP100 & WSP100 & WSP72 & WSP60 & WSP35 & MSP100 & MSP52 & MSP10 \\
\hline Parameter & Units & $\begin{array}{l}\text { Wood } \\
\text { Pellet } \\
100 \%\end{array}$ & $\begin{array}{c}\text { Wheat } \\
\text { Straw } \\
\text { Pellet } \\
100 \%\end{array}$ & $\begin{array}{c}\text { Wheat } \\
\text { Straw } \\
\text { Pellet } \\
72 \%\end{array}$ & $\begin{array}{c}\text { Wheat } \\
\text { Straw } \\
\text { Pellet } \\
60 \%\end{array}$ & $\begin{array}{c}\text { Wheat } \\
\text { Straw } \\
\text { Pellet } \\
35 \%\end{array}$ & $\begin{array}{c}\text { Maize } \\
\text { Stalk } \\
\text { Pellet } \\
100 \%\end{array}$ & $\begin{array}{c}\text { Maize } \\
\text { Stalk } \\
\text { Pellet } \\
52 \%\end{array}$ & $\begin{array}{c}\text { Maize } \\
\text { Stalk } \\
\text { Pellet } \\
10 \%\end{array}$ \\
\hline \multicolumn{10}{|c|}{ Pellets properties } \\
\hline Durability & \% a.r. & 91.3 & 97.7 & 96.6 & 95.9 & 92.6 & 96.1 & 97.4 & \\
\hline Bulk density ${ }^{a}$ & $\mathrm{~kg} / \mathrm{m}^{3}$ d.b. & 510.2 & 667.3 & 604.3 & 562.2 & 460.0 & 638.1 & 655.6 & 587.6 \\
\hline Fines percentage & $<3.15 \mathrm{~mm}$ & 3.07 & 1.76 & 3.10 & 1.52 & 4.41 & 2.44 & 0.98 & 1.27 \\
\hline \multicolumn{10}{|c|}{ Proximate analysis } \\
\hline Moisture ${ }^{b}$ & $\%$ a.r. & 7.6 & 4.8 & 6.4 & 6.7 & 10.2 & 5.5 & 5.5 & 7.6 \\
\hline Volatile matter ${ }^{\mathrm{c}}$ & $\%$ d.b. & 81.0 & 73.8 & 74.5 & 74.9 & 74.7 & 71.7 & 72.9 & 74.8 \\
\hline Fixed carbon ${ }^{d}$ & $\%$ d.b. & 18.0 & 20.1 & 21.6 & 22.0 & 21.2 & 15.8 & 20.9 & 22.1 \\
\hline Ash $^{\mathrm{e}}$ & $\%$ d.b. & 1.0 & 6.1 & 3.9 & 3.1 & 4.1 & 12.5 & 6.2 & 3.2 \\
\hline \multicolumn{10}{|c|}{ Ultimate analysis } \\
\hline$C^{f}$ & $\%$ d.b. & 51.90 & 45.50 & 48.10 & 49.20 & 49.30 & 42.60 & 48.10 & 51.4 \\
\hline $\mathrm{H}^{\mathrm{f}}$ & $\%$ d.b. & 5.80 & 5.80 & 5.90 & 6.00 & 5.90 & 5.20 & 5.80 & 5.8 \\
\hline$N^{f}$ & $\%$ d.b. & 0.13 & 0.42 & 0.30 & 0.50 & 0.29 & 0.82 & 0.44 & 0.27 \\
\hline Sg & $\%$ d.b. & 0.01 & 0.08 & 0.08 & 0.03 & 0.05 & 0.13 & 0.03 & 0.03 \\
\hline $\mathrm{Cl}^{\mathrm{g}}$ & $\%$ d.b. & 0.02 & 0.19 & 0.06 & 0.05 & 0.05 & 0.53 & 0.20 & 0.06 \\
\hline $\mathrm{O}^{\mathrm{c}}$ & $\%$ d.b. & 41.00 & 41.91 & 41.66 & 41.12 & 40.32 & 38.20 & 39.23 & 37.7 \\
\hline \multicolumn{10}{|c|}{ Heating value } \\
\hline $\begin{array}{c}\text { Low heating } \\
\text { value }\end{array}$ & kWh/kga.r. & 4.90 & 4.43 & 4.59 & 4.67 & 4.50 & 4.00 & 4.61 & 4.70 \\
\hline
\end{tabular}

${ }^{\mathrm{a}}$ EN 15103:2009, b EN-ISO 18134:2016, ${ }^{\mathrm{c}}$ EN-ISO 18123:2016, ${ }^{\mathrm{d}}$ Calculated, e EN-ISO 18122:2016, ${ }^{\mathrm{f}}$ EN-ISO 16948:2015, g EN-ISO 16994:2015, h EN-ISO 14918:2011.

\subsubsection{Prediction of Ash Behaviour}

As it has already been noted, the main problems that herbaceous fuels present when they are commercialized are directly related to its ash, both in quantity and quality. The former will need to have an adequate cleaning system. For the latter, it will be crucial to consider the composition and how it contributes to the greater or lesser degree of these problems and the need to adapt the operating conditions to minimize them, which is essential to achieve a suitable boiler operation.

Research studies carried out during the last decades have coincided in pointing out the critical influence of ash chemical composition [16-26] in relation with those problems associated with thermal conversion.

Table 3 includes ash composition of the different fuels. It can be seen that WP100 has a higher $\mathrm{Ca}$ and $\mathrm{Mg}$ content compared to agropellets, especially with those containing a significant percentage of straw (WSP family). It is known that, in general, in grate combustion, an increase in $\mathrm{Ca}$ and $\mathrm{Mg}$ content has a positive influence in ash melting temperatures [27]. Thus, for a given amount of $\mathrm{Si}$, as the ratio between alkaline earth and alkali metals increases, these melting temperatures are also increasing, possibly reducing the tendency of sintering [24]. 
Table 3. Ash fuel properties (\% d.b.: weight percentage in dry basis).

\begin{tabular}{|c|c|c|c|c|c|c|c|c|c|}
\hline & & WP100 & WSP100 & WSP72 & WSP60 & WSP35 & MSP100 & MSP52 & MSP10 \\
\hline Parameter & Units & $\begin{array}{l}\text { Wood } \\
\text { Pellet } \\
100 \%\end{array}$ & $\begin{array}{l}\text { Wheat } \\
\text { Straw } \\
\text { Pellet } \\
100 \%\end{array}$ & $\begin{array}{c}\text { Wheat } \\
\text { Straw } \\
\text { Pellet } \\
72 \%\end{array}$ & $\begin{array}{c}\text { Wheat } \\
\text { Straw } \\
\text { Pellet } \\
60 \%\end{array}$ & $\begin{array}{c}\text { Wheat } \\
\text { Straw } \\
\text { Pellet } \\
35 \%\end{array}$ & $\begin{array}{l}\text { Maize } \\
\text { Stalk } \\
\text { Pellet } \\
100 \%\end{array}$ & $\begin{array}{c}\text { Maize } \\
\text { Stalk } \\
\text { Pellet } \\
52 \%\end{array}$ & $\begin{array}{c}\text { Maize } \\
\text { Stalk } \\
\text { Pellet } \\
10 \%\end{array}$ \\
\hline \multicolumn{10}{|c|}{ Ash analysis ${ }^{a}$} \\
\hline $\mathrm{Na}_{2} \mathrm{O}$ & $\%$ d.b. & 1.5 & 0.27 & 0.58 & 0.51 & 0.89 & 0.64 & 0.67 & 1.17 \\
\hline $\mathrm{MgO}$ & $\%$ d.b. & 9.06 & 3.04 & 2.86 & 2.91 & 2.69 & 7.99 & 6.1 & 6.77 \\
\hline $\mathrm{Al}_{2} \mathrm{O}_{3}$ & $\%$ d.b. & 5.62 & 1.19 & 1.75 & 2.13 & 5.88 & 5.81 & 5.82 & 7.00 \\
\hline $\mathrm{SiO}_{2}$ & $\%$ d.b. & 16.55 & 55.81 & 38.11 & 34.57 & 35.00 & 38.94 & 38.38 & 27.71 \\
\hline $\mathrm{P}_{2} \mathrm{O}_{5}$ & $\%$ d.b. & 3.89 & 2.62 & 4.36 & 3.84 & 2.96 & 3.61 & 4.17 & 3.65 \\
\hline $\mathrm{K}_{2} \mathrm{O}$ & $\%$ d.b. & 13.27 & 21.71 & 27.52 & 28.48 & 23.87 & 11.05 & 11.75 & 11.29 \\
\hline $\mathrm{CaO}$ & $\%$ d.b. & 41.02 & 9.88 & 17.50 & 20.27 & 21.6 & 21.95 & 24.97 & 35.06 \\
\hline $\mathrm{TiO}_{2}$ & $\%$ d.b. & 0.35 & 0.08 & 0.10 & 0.12 & 0.21 & 0.3 & 0.29 & 0.38 \\
\hline $\mathrm{Fe}_{2} \mathrm{O}_{3}$ & $\%$ d.b. & 3.85 & 0.57 & 0.85 & 1.03 & 1.81 & 2.35 & 2.56 & 3.17 \\
\hline \multicolumn{10}{|c|}{ Ash fusibility temperatures $b$} \\
\hline $\begin{array}{c}\text { Shrinkage } \\
\text { starting (SST) }\end{array}$ & ${ }^{\circ} \mathrm{C}$ & 1160 & - & 1010 & 1040 & 1080 & 1190 & 1150 & 1190 \\
\hline $\begin{array}{l}\text { Deformation } \\
\text { (DT) }\end{array}$ & ${ }^{\circ} \mathrm{C}$ & 1230 & - & 1030 & 1060 & 1130 & 1200 & 1160 & 1200 \\
\hline $\begin{array}{l}\text { Hemispherical } \\
\text { (HT) }\end{array}$ & ${ }^{\circ} \mathrm{C}$ & 1370 & - & 1130 & 1150 & 1130 & 1230 & 1220 & 1220 \\
\hline $\begin{array}{l}\text { Flow } \\
\text { (FT) }\end{array}$ & ${ }^{\circ} \mathrm{C}$ & 1430 & - & 1150 & 1160 & 1160 & 1240 & 1230 & 1230 \\
\hline
\end{tabular}

${ }^{a}$ EN-ISO 16967:2015, ${ }^{\text {b CEN } / T S ~ 15370-1: 2006 . ~}$

Si content is more than twice in all agropellets and more than three times in the case of WSP100, compared to WP100. The high values detected in the agropellets may be related either to contamination in the raw material treatment or in the pelletizing process itself [28]. On the other hand, $\mathrm{SiO}_{2}$ percentages in ash over $20-25 \%$ suggest sintering problems with these fuels [28]. In addition, the WSP family has a much higher percentage of $\mathrm{K}$ and $\mathrm{Na}$ than the rest, which, together with the high Si content, suggests the potassium silicate's formation, directly related to major sintering problems [29].

As for $\mathrm{Cl}$ and S content (Table 2), the high percentage that MSP100 and WSP100 present compared to the others (principally MSP100) should be noted, and how they decrease when the mix with wood is carried out. Both $\mathrm{Cl}$ and $\mathrm{S}$ are related with gaseous emissions [30] and possible deposition and corrosion problems [31].

On the other hand, sintering problems are attributed to low melting temperatures of the ash [32]. Although there are no important differences among the values (Table 3), the WSP family has the lowest melting temperatures, while WP100 has the highest (except for SST, which is similar to the one of the MSP family). These temperatures are directly associated with the fuel composition. Therefore, it has been verified that there is a linear relationship between the ash-sintering temperature (SST) and the ratio defined as: $(\mathrm{Si}+\mathrm{P}+\mathrm{K}) /(\mathrm{Ca}+\mathrm{Mg})$, so that the higher the latter, the lower the temperature [33]. This relationship is also confirmed for the fuels analysed (see Figure 1). In this case, the ratio has been slightly modified, including $\mathrm{Na}$ (since $\mathrm{Na}$ has a similar behaviour of $\mathrm{K}$ [27]) in the numerator. It can be seen how the WSP family presents a higher ratio, which increases as the percentage of herbaceous material in the blend is raised. In this family, although the SST of the WSP100 is unknown, taking into account the abovementioned linear relationship and that the value of the ratio for this fuel is greater than 2.1, the lowest SST is foreseen, thus greater sintering problems can be expected. 


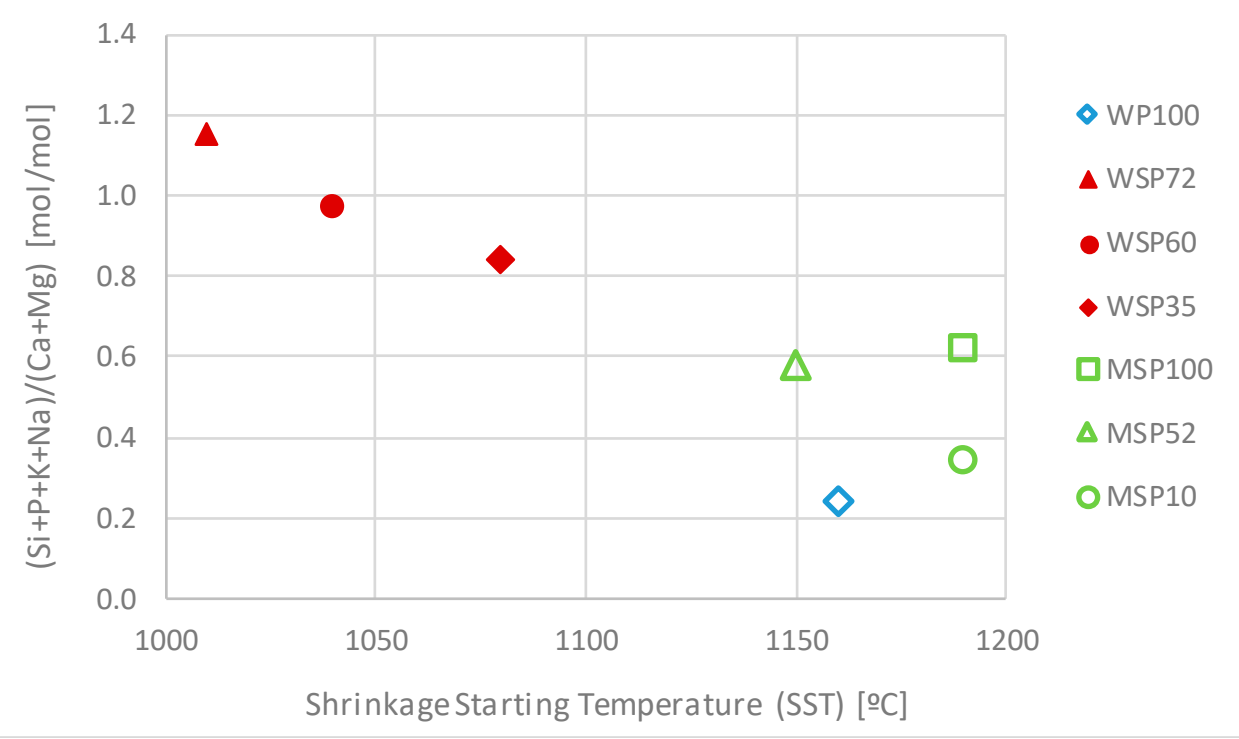

Figure 1. Ratio $(\mathrm{Si}+\mathrm{P}+\mathrm{K}+\mathrm{Na}) /(\mathrm{Ca}+\mathrm{Mg})$ versus SST.

The results obtained for the MSP family indicate a lower tendency to sintering, although the different compositions of the ash of the blended pellets do not exactly follow the expected relationship with the proportion defined in the blends, possibly due to the usual heterogeneity of biomass. In fact, MSP100 and MSP52 have alike percentages of $\mathrm{K}+\mathrm{Na}, \mathrm{Ca}+\mathrm{Mg}$, and $\mathrm{Si}$, and their ratio are very similar, so the sintering tendency between them may not show noticeable differences. As for WP100, it is the one that presents the lower ratio, although its SST is lower than for the MSP family, which could mean a greater tendency to sintering. However, it should be kept in mind that the difference between SST and DT (see Table 3 ) is bigger than for the rest of fuels $\left(70^{\circ} \mathrm{C}\right.$ versus $\left.10^{\circ} \mathrm{C}\right)$. Additionally, this gradient also affects a greater difference, will imply a lower probability of sintering problems occurring [34].

Therefore, when predicting sintering and deposition phenomena, it is not only important to know the elemental composition of ash but also the relative relationship that exists between their elements. For this reason, ratios or indices are used. Based on their value, they allow the prediction of the fuel behaviour $[33,35,36]$.

Taking into account the research team experience and attempting to minimise the indices limitations associated to their use with blended pellets, six indices were selected [35]. Formulas are included in Tables 4 and 5, as well as the reference values for both sintering and deposition indexes interpretation.

From the properties of fuels shown in Table 3, it is possible to calculate these predictive indices and compare their value with reference values, depicted in Tables 4 and 5, for each phenomenon (sintering and deposition). Table 6 shows the results for sintering. The colour scale indicates the greater or lesser tendency to sintering predicted by each index for each fuel. 
Table 4. Predictive indices for sintering.

\begin{tabular}{|c|c|c|c|c|}
\hline Index & Expression & Reference Value & $\begin{array}{l}\text { Interpretation of the } \\
\text { Reference Value }\end{array}$ & Reference \\
\hline $\begin{array}{c}\text { Basic to acidic } \\
\text { compounds ratio (B/A) }\end{array}$ & $\frac{\mathrm{B}}{\mathrm{A}}=\frac{\left(\mathrm{Fe}_{2} \mathrm{O}_{3}+\mathrm{CaO}+\mathrm{MgO}+\mathrm{Na}_{2} \mathrm{O}+\mathrm{K}_{2} \mathrm{O}\right)}{\left(\mathrm{SiO}_{2}+\mathrm{Al}_{2} \mathrm{O}_{3}+\mathrm{TiO}_{2}\right)}$ & $\begin{array}{c}<0.5 \\
0.5-1 \\
1-1.75 \\
\geq 1.75\end{array}$ & $\begin{array}{l}\text { Low inclination } \\
\text { Medium inclination } \\
\text { High inclination } \\
\text { Severe inclination }\end{array}$ & [37] \\
\hline Babcock Index (Rs) & $\mathrm{R}_{\mathrm{S}}=\frac{\mathrm{B}}{\mathrm{A}} \cdot \mathrm{S}^{\mathrm{d}}$ & $\begin{array}{l}<0.6 \\
0.6-2 \\
2-2.6 \\
>2.6\end{array}$ & $\begin{array}{l}\text { Low inclination } \\
\text { Medium inclination } \\
\text { High inclination } \\
\text { Extremely high } \\
\text { inclination }\end{array}$ & [36] \\
\hline Slag Viscosity Index (Sr) & $\mathrm{S}_{\mathrm{r}}=100 \cdot \frac{\mathrm{SiO}_{2}}{\mathrm{SiO}_{2}+\mathrm{Fe}_{2} \mathrm{O}_{3}+\mathrm{CaO}+\mathrm{MgO}}$ & $\begin{array}{c}>72 \\
65-72 \\
\leq 65 \\
<30 \\
30<\mathrm{Sr}<70 \\
>70\end{array}$ & $\begin{array}{l}\text { Low inclination } \\
\text { Medium inclination } \\
\text { High inclination } \\
\text { No risk of sintering } \\
\text { Medium risk } \\
\text { High risk of sintering }\end{array}$ & {$[36]$} \\
\hline Alkali oxides index (I) & $\mathrm{I}=\frac{(\mathrm{CaO}+\mathrm{MgO})}{\left(\mathrm{Na}_{2} \mathrm{O}+\mathrm{K}_{2} \mathrm{O}\right)}$ & $>2$ & No risk of sintering. & [39] \\
\hline Alkali index (AI) & $\mathrm{AI}=\frac{\left(\mathrm{K}_{2} \mathrm{O}+\mathrm{Na}_{2} \mathrm{O}\right) \cdot \mathrm{Ash}_{\text {d.b. }}}{\mathrm{HHV}_{\text {d.b. }}}$ & $>0.34 \mathrm{~kg}$ alkali $/ \mathrm{GJ}$ & High risk of sintering & [40] \\
\hline Fouling Index (Fu) & $\mathrm{Fu}=\frac{\mathrm{B}}{\mathrm{A}} \cdot\left(\mathrm{Na}_{2} \mathrm{O}+\mathrm{K}_{2} \mathrm{O}\right)$ & $>40$ & $\begin{array}{l}\text { High risk of sintered } \\
\text { deposits. }\end{array}$ & {$[10]$} \\
\hline
\end{tabular}

Table 5. Predictive indices for deposition.

\begin{tabular}{|c|c|c|c|c|}
\hline Index & Expression & Reference Value & $\begin{array}{l}\text { Interpretation of the } \\
\text { Reference Value }\end{array}$ & Reference \\
\hline Alkali index (AI) & $\mathrm{AI}=\frac{\left(\mathrm{K}_{2} \mathrm{O}+\mathrm{Na}_{2} \mathrm{O}\right) \cdot \mathrm{Ash}_{\text {d.b. }}}{\mathrm{HHV} \mathrm{V}_{\text {d.b. }}}$ & $\begin{array}{l}>0.17 \mathrm{~kg} \text { alkali/GJ } \\
>0.34 \mathrm{~kg} \text { alkali } / \mathrm{GJ}\end{array}$ & $\begin{array}{l}\text { Possible deposition risk } \\
\text { High deposition risk }\end{array}$ & [41] \\
\hline Fouling Index (Fu) & $\mathrm{Fu}=\frac{\mathrm{B}}{\mathrm{A}} \cdot\left(\mathrm{Na}_{2} \mathrm{O}+\mathrm{K}_{2} \mathrm{O}\right)$ & $\begin{array}{l}\leq 0.6 \\
0.6-40 \\
>40\end{array}$ & $\begin{array}{c}\text { Low deposition } \\
\text { inclination } \\
\text { High deposition } \\
\text { inclination } \\
\text { Extremely high } \\
\text { tendency of deposition }\end{array}$ & [10] \\
\hline
\end{tabular}

Table 6. Indices values to analyse sintering.

\begin{tabular}{cccccccccc}
\hline Kerrypnx & & WP100 & WSP100 & WSP72 & WSP60 & WSP35 & MSP100 & MSP52 & MSP10 \\
\hline & B/A & 3.05 & 0.62 & 1.23 & 1.44 & 1.24 & 0.98 & 1.04 & 1.64 \\
& Rs & 0.03 & 0.05 & 0.10 & 0.04 & 0.06 & 0.12 & 0.03 & 0.05 \\
Sintering & Sr $^{\text {(a) }}$ & 23.48 & 80.53 & 64.24 & 58.81 & 57.28 & 54.67 & 53.30 & 38.11 \\
Indices & Sr $^{\text {(b) }}$ & 23.48 & 80.53 & 64.24 & 58.81 & 57.28 & 54.67 & 53.30 & 38.11 \\
& $\mathbf{I}$ & 3.39 & 0.59 & 0.72 & 0.80 & 0.98 & 2.56 & 2.50 & 3.36 \\
& AI & 0.08 & 0.79 & 0.61 & 0.50 & 0.57 & 0.94 & 0.43 & 0.22 \\
& Fu & 45.06 & 13.66 & 34.67 & 41.89 & 30.65 & 11.41 & 12.86 & 20.40 \\
\hline & Risk & Undefined & \multicolumn{2}{c}{ Low } & \multicolumn{2}{c}{ Medium } & High & Very high \\
\hline
\end{tabular}

(a) Prediction made taking into account the limits set for Sr index in $36,{ }^{(b)}$ Prediction made taking into account the new limits set for Sr index in [38].

Considering the results achieved, the first conclusion that can be drawn is that the indices present contradictory results for sintering, which is in agreement with other authors' conclusions [42]. Thus, while the Rs indices assume that no sintering problems will occur 
with any fuels $(\mathrm{Rs}<0.6)$, the indices AI predict the opposite in six of them $(\mathrm{AI}>0.34)$. In addition, the prediction changes radically depending on the chosen limits (see $\mathrm{Sr}$ ). On the other hand, there are no significant differences predicted between the behaviour of the woody pellet (WP100) and the agropellets, but it is well known that their behaviour is significantly different.

As for deposition prediction, the alkali index (AI) and Fu index are usually used. Table 7 shows the values obtained for the fuels analysed, as well as the prediction of their behaviour. Considering the limits for AI [40,41], WP100 is the only fuel that would not present problems related to the deposition phenomena. Agropellets would have a high tendency to deposition, and only MSP10, containing a low percentage of herbaceous material, would be in the intermediate zone. In the case of Fu index, taking into account their limits value [36], WSP60 and WP100 would be the fuels with the greatest foreseeable deposition problems. Again, the indices give conflicting predictions, as the AI value indicates the opposite for the WP100.

Table 7. Indices values to analyse deposition.

\begin{tabular}{ccccccccc}
\hline & WP100 & WSP100 & WSP72 & WSP60 & WSP35 & MSP100 & MSP52 & MSP10 \\
\hline AI & 0.08 & 0.79 & 0.61 & 0.50 & 0.57 & 0.94 & 0.43 \\
Fu & 45.06 & 13.66 & 34.67 & 41.89 & 30.65 & 11.41 & 12.86 & 20.40 \\
\hline Risk & \multicolumn{8}{c}{ Low } \\
\hline
\end{tabular}

Although some of these criteria are quite representative, in order to evaluate the quality of the blends, these results need to be validated during the combustion tests.

\subsection{Methods}

\subsubsection{Reactor}

In order to perform the combustion tests, an experimental fixed bed reactor at CIRCE's laboratory was used. The main variable in the fixed bed commercial equipment is space, since by different means, biomass moves through the grate while experiencing several processes: heating and drying of the fuel, volatiles release, and, finally, combustion of the char. However, in laboratory reactors, fuel undergoes these processes successively [43]. Fuel is fed in batches, i.e., a certain amount is introduced in the reactor and, after combustion ash is removed, to add a new load of fuel. This operation mode greatly simplifies the design, facilitates data acquisition, and allows better control of the reactor.

The one used in this case (see Figure 2) consists of a vertical cylindrical combustor chamber having a height of $1700 \mathrm{~mm}$ and an inner diameter of $200 \mathrm{~mm}$. At the bottom, there is a grate with $3 \mathrm{~mm}$ diameter holes equidistantly separated, resulting in a porosity of $4.5 \%$. Primary air is injected from the bottom, through the orifices in the grate, by means of a fan equipped with a variable-frequency drive that allows adjustment of the air flow. Since tests were carried out at a controlled temperature of the primary air $\left(\cong 25^{\circ} \mathrm{C}\right)$, it was arranged to use a refrigerator or an electrical resistor at the air inlet to cool down or heat up. The reactor was instrumented with fifteen $\mathrm{N}$ thermocouples used to know the temperatures' evolution both in the bed and in the freeboard. For identification purposes, they are numbered from TC1, the closest to the grate, to TC15, located in the upper part of the reactor (see Figure 2). For more details about reactor characteristics, operation, and regulations, see [44]. 


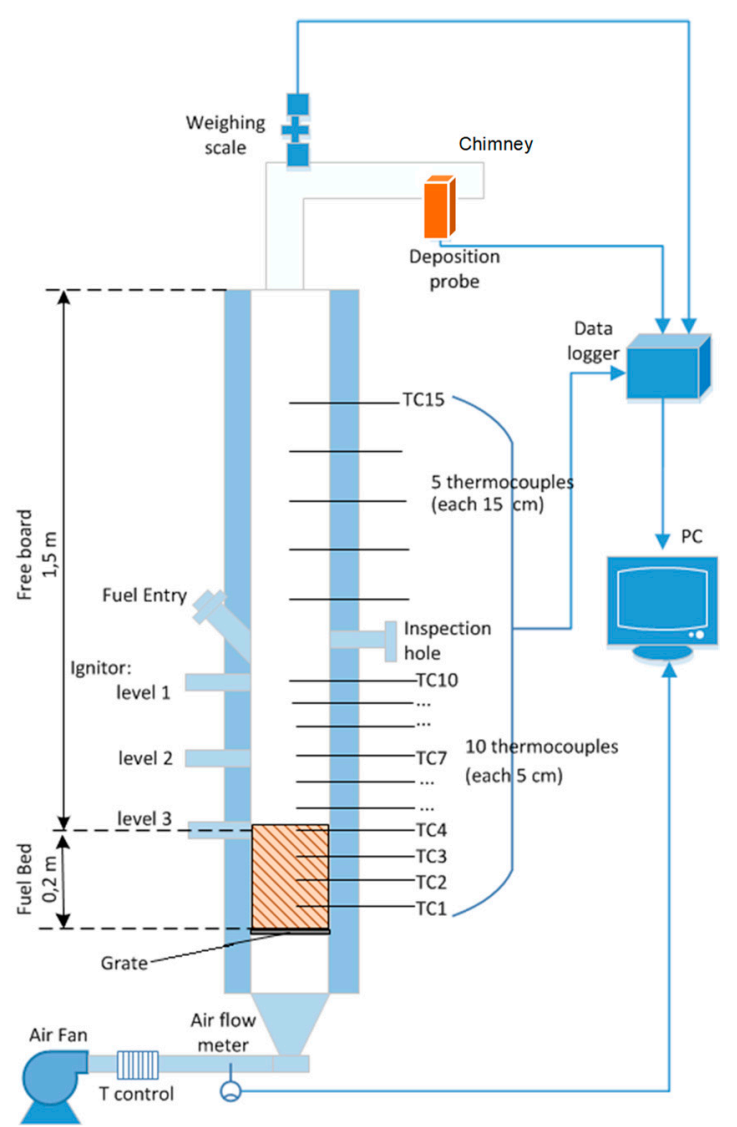

Figure 2. Scheme of the experimental test facility.

In addition, the facility is completed by installing a deposition probe, constructed with high-temperature resistant stainless steel, with a removable sampling ring in the chimney of the reactor (see further description in [45]). The sampling ring used to extract deposits samples has a length of about $40 \mathrm{~mm}$ and a diameter of about $35 \mathrm{~mm}$. It is cooled by compressed air, allowing it to keep its surface at an appropriate temperature for studying deposition phenomenon $\left(335 \pm 25^{\circ} \mathrm{C}\right.$. on average). Prior to the experiment, the removable sampling ring is cleaned, dried, measured, and weighed. Once extracted, the dirty sampling ring is dried and weighed again to obtain the amount of mass deposited. Using this weight value, the surface of the sampling ring, and the duration of the test, it is possible to calculate the deposition rate $\left(\mathrm{DR}, \mathrm{g} \cdot \mathrm{m}^{-2} \cdot \mathrm{h}^{-1}\right)$, allowing to estimate the tendency to fouling of each studied fuel $[46,47]$.

Once combustion is completed and the reactor has cooled down, bottom ash is collected from the top of the grate for weighing and classification. The determination of sintering degree with the sieving and weighting bottom ash fractions has been used in several studies to determine the sintering tendency of a fuel [31,48-52]. In this case, the following categories, based on a revised classification of sintering status defined in a previous work [24,51], are used: S1, pass through a $3.15 \mathrm{~mm}$ sieve and is considered as not sintered; $\mathrm{S} 2$, do not pass the $3.15 \mathrm{~mm}$ sieve, but is easily disaggregated by hand and present a low sintering status; S3, do not pass the $3.15 \mathrm{~mm}$ sieve, is difficult to disaggregate by hand, and presents a high sintering status. Since the difference between S2 and S3 is subjective, a fraction $\mathrm{S} 2 / 3$, encompassing both classes, is used. The sintering degree of a fuel will be calculated as the percentage of this last fraction $(\mathrm{S} 2 / 3)$, in respect to the total ash introduced with the fuel in each test. 


\subsubsection{Test Features}

A total of 68 successful tests were carried out with the eight fuels (between 5-10 tests per fuel). The parameters that were changed during the tests were the type of fuel and the inlet air flow expressed as the air mass flow by unit area of the grate $\left(\mathrm{PA}, \mathrm{kg} \cdot \mathrm{m}^{-2} \cdot \mathrm{s}^{-1}\right)$ studying, arranged from 0.25 to $0.55 \mathrm{~kg} \cdot \mathrm{m}^{-2} \cdot \mathrm{s}^{-1}$. Depending on the air flow supply a different excess air ratio $(\lambda)$ was obtained for each fuel, and therefore three regimes might appear with different behaviour regarding the ignition front propagation $[43,49,50,52]$ :

1. Regime I (under stoichiometric air): the deficient amount of oxygen is consumed completely by the char and volatiles material [52]. Thus, the velocity of the ignition front is controlled by the supply of oxygen, rising as the amount of air increases [49]. In some cases, the combustion in this regimen may be unstable due to the limitation regarding the oxygen content.

2. Regime II (around stoichiometric air): in this regime, the velocity of the ignition front is almost independent of the air flow rate [49].

3. Regime III (highly above stochiometric air): the air flow increases even more, the volatiles are diluted, and the convective cooling slows down the process. If the heat released in the bed is enough, the front propagation will continue and if not, it will cause the extinction of the flame [49,52].

The sintering phenomena (which is one of the main disadvantages derived from the use of these type of resources) takes place at the bottom of the boiler where the primary air is injected (which can imply $\lambda$ lower or higher than 1, depending on whether the boiler has secondary air inlets or not). For this reason, the experimental test was designed in order to simulate the air flow of the primary air, and therefore assess a scenario fairly close to reality regarding the sintering phenomena occurrence. Nevertheless, when deposition phenomena are analysed, which take place at the top of the boiler, the test with $\lambda<1$ does not make sense, since the combustion is incomplete (because the experimental reactor does not have a secondary air flow, that guarantees the excess air $(\lambda>1)$, necessary in operating conditions of actual facilities). For that reason, tests with $\lambda<1$ are not going to be considered in the sections where the deposition phenomena are assessed.

The inlet air temperature $\left(\mathrm{Ta},{ }^{\circ} \mathrm{C}\right)$ was fixed around $25^{\circ} \mathrm{C}$. The amount of biomass fed to the reactor in each test was such that the total bed height was $210 \mathrm{~mm}$. In this way, thermocouples TC1 to TC4 were initially set inside the bed. The tests were carried out following the same protocol with the eight fuels [49].

From the inlet parameters (PA and Ta), the measured variables, the geometrical data, and the fuel analysis, the following parameters were calculated:

1. Velocity of the ignition front $\left(\mathrm{v}_{\mathrm{ir}}, \mathrm{mm} \cdot \mathrm{s}^{-1}\right)$ : it is a measure of how fast the flame progresses along the fuel bed height. It is calculated from the time that it takes for consecutive thermocouples (TC3, TC2, and TC1) to reach a pre-determined temperature (reference value $500{ }^{\circ} \mathrm{C}$ ) and the known distance between them $(50 \mathrm{~mm})$.

2. Ignition rate $\left(\mathrm{m}_{\mathrm{ir}}, \mathrm{kg} \cdot \mathrm{m}^{-2} \cdot \mathrm{s}^{-1}\right)$ : it is obtained by multiplying the velocity of the ignition front $\left(\mathrm{v}_{\mathrm{ir}}\right)$ by the bulk density of the fuel, which allows comparison of the combustion behaviour of different fuels [49]. It is expressed in mass loss per grate surface area (ignition front plane area) and time.

3. Excess air ratio $(\lambda)$ : once the ignition rate $\left(\mathrm{m}_{\mathrm{ir}}\right)$ has been determined, the excess air ratio for each test can be calculated from PA and the stoichiometric air-to-fuel ratio of the studied fuel.

4. Mean flame temperature $\left(\mathrm{T}_{\mathrm{if}},{ }^{\circ} \mathrm{C}\right)$ : to compute this temperature, a time interval of stable combustion is defined between the instant the first TC inside the bed reaches $500{ }^{\circ} \mathrm{C}$ and the moment TC1 (near the grate) reaches the same temperature. The mean value of the maximum temperature of these TC is the mean flame temperature.

5. Deposition rate $\left.\left(\mathrm{DR}, \mathrm{g} \cdot \mathrm{m}^{-2} \cdot \mathrm{h}^{-1}\right)\right)$ : it is obtained from the mass of ash deposits collected, the area of the ring surface, and the duration of the exposition. 
6. Sintering degree (\%): once the collected S2/3 fraction is weighed it is obtained as a percentage of the total ash fed to the reactor with the fuel.

\subsubsection{Statistical Analysis}

To determine the goodness of a certain linear correlation, a statistical analysis through the estimation of the Pearson's correlation coefficient (r) and its corresponding $p$-value $(p)$ was performed. The correlation will be considered statistically significant when $p<0.05$.

\section{Results}

\subsection{Combustion Parameters}

In this section, the combustion behaviour is evaluated for the eight fuels tested at five different flows of air and one repetition each to ensure replicability.

Figure 3 reflects $\lambda$ obtained as a result of the five primary airs studied for each fuel, and Figure 4 depicts the tendency regarding the $m_{i r}$ vs. $\lambda$ for the MSP family and the WSP family compared with the reference fuel, WP100.
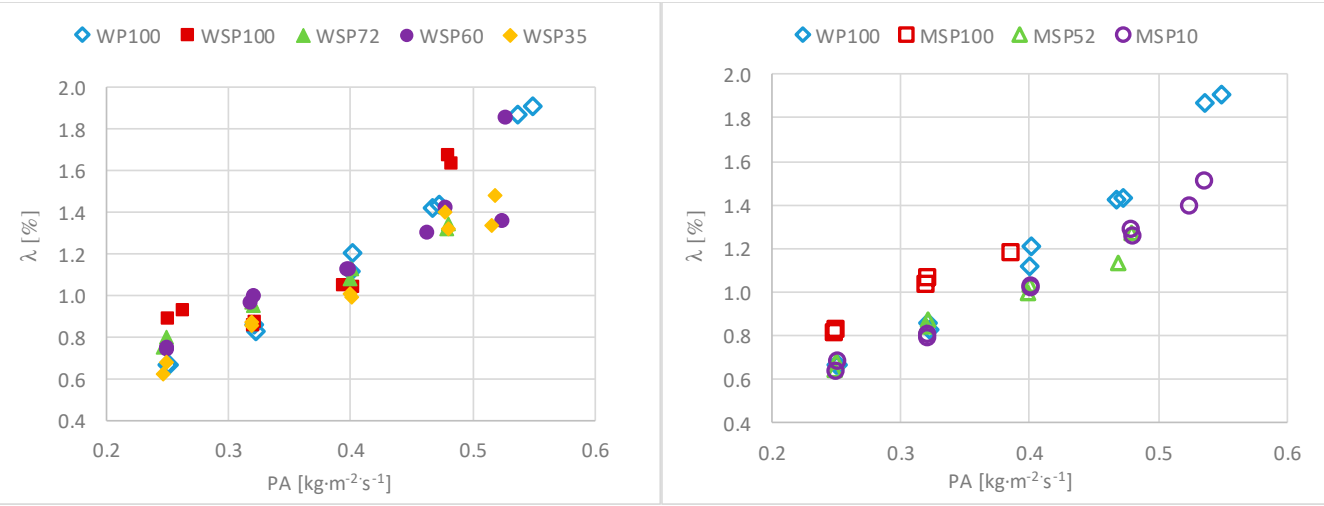

Figure 3. Values of $\lambda$ for the different primary air studied. Comparison between the WP100 and WSP family (left) and the MSP family (right).
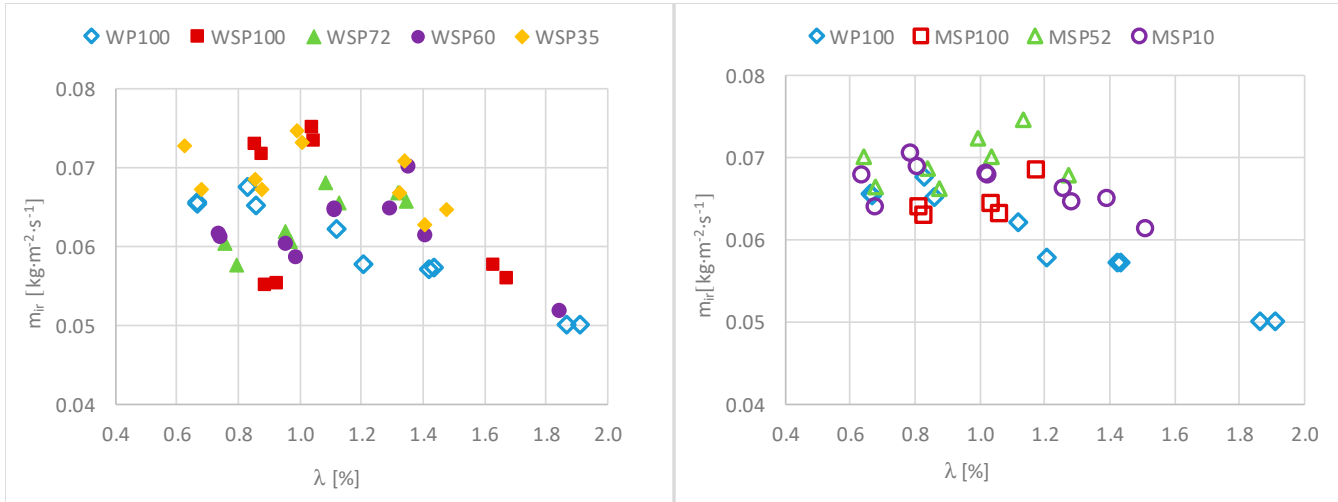

Figure 4. Ignition rates vs. $\lambda$. Comparison between the WP100 and WSP family (left) and the MSP family (right).

The results obtained showed different values of $\lambda$ for each fuel tested despite working with the same PA, since the velocity of the ignition obtained in each test was different. The tendency in all cases showed a linear increase of the $\lambda$ obtained from the test with an increase in the value of the primary air (all correlations with $r>0.93, p<0.001$, except WSP100 with $r=0.88, p=0.004$ ). However, it is necessary to highlight the unexpected $\lambda$ values found in the case of the WSP100 working with a primary air of $0.25 \mathrm{~kg} / \mathrm{m}^{2} \mathrm{~s}$ since the fuel was burnt slower than expected, as is reflected in the ignition rate values obtained in these tests (Figure 4). 
Additionally, it can be seen in Figure 3 that in general, from $0.40 \mathrm{~kg} / \mathrm{m}^{2} \mathrm{~s}$ the dispersion obtained between the two tests with the same PA is higher, which can be an indicator of the transition from regimen II to III.

Closely related to this fact, it can be highlighted that for fuels with a high percentage of herbaceous biomass (MSP100, MSP52, WSP100, and WSP72) it was not possible to complete the tests with a high PA, since the high quantity of air produced switched off the flame.

As can be seen in Figure 4, the ignition rates follow a very similar pattern at a qualitative level and in general in accordance with what is stated in Section 3.2: a possible linear increase with the primary air, according with the regime I (although, given the low number of data available in this regime, it is not possible to state a correlation statistically significant), a further stabilisation during the regime II (presenting higher rates of ignition), and a reduction for high values of air in the regimen III (although only for WP100, WSP100, WSP35, and MSP10 are the correlations statistically significant), producing the extinction of the flame in some cases (mainly in the blends with high percentage of herbaceous material, as was previously mentioned). However, WP100 presents a linear decrease of the ignition rate with the increase of the primary air. In this regard, it seems that the results obtained from the test at $0.25 \mathrm{~kg} / \mathrm{m}^{2} \mathrm{~s}$ for WP100 were unexpected. These higher values of ignition front imply that the material was burnt very fast, and taking into account the higher values of unburnt material measured (the unburnt values in these two tests were around 9\% while in the rest of the tests carried out with similar fuel the average value it is lower than 3.5\%) and deposition rates (DR values obtained for WP100 for the two test performed with the minimum $\lambda$ are 35.7 and $29.9 \mathrm{~g} \cdot \mathrm{m}-2 \cdot \mathrm{h}-1$ ) obtained in these tests compared with the other tests for WP100, this suggests that the combustion with this air was uncontrolled, which may be due to the aforementioned instability that can occur in combustion during regime I.

At a quantitative level, many differences can be observed. In Figure 4, WSP35 and MSP52 showed the highest values of ignition rates for blended agropellets. In addition, the values of ignition rate for these fuels were stable in a wide range of air. On the contrary, the values of ignition rates for MSP100 and WSP100 showed large variations along the range of air tested.

$\mathrm{T}_{\text {if }}$ profile is a clear indicator of the combustion process. Regarding the tendency of this temperature (Figure 5), it was similar to the one obtained in the ignition front, being the maximum around the stoichiometric air. As stated before, the fuel WP100 presents an unexpected behaviour as a result of the uncontrolled combustion for $\lambda<1$. $\mathrm{T}_{\text {if }}$ achieved for the blended pellets were in all cases higher than the WP100, being higher and more stable in the MSP family than in the WSP family.

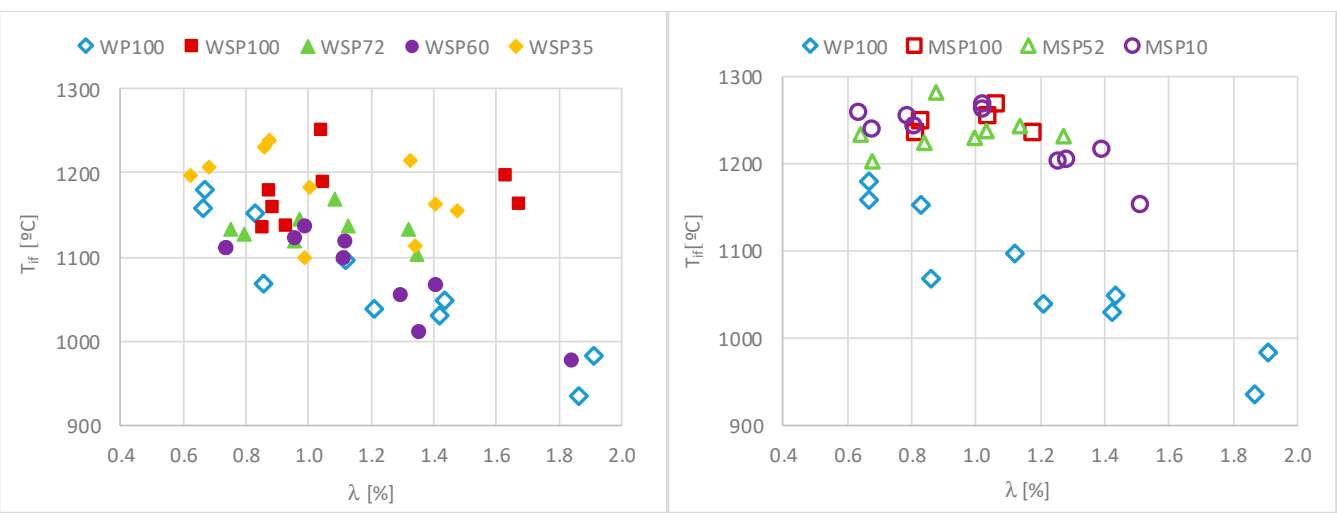

Figure 5. $\mathrm{T}_{\text {if }}$ temperature vs. $\lambda$. Comparison between the WP100 and WSP family (left) and the MSP family (right).

It can be observed as for $\lambda>1$, when $\lambda$ is increased in general there is a decrease in the $\mathrm{T}_{\text {if }}$ temperature, finding a statistically significant correlation for WP100 $((\mathrm{r}=-0.90$, $p<0.013)$, WSP60 ( $\mathrm{r}=-0.88, p<0.020), \operatorname{MSP} 100(\mathrm{r}=-0.98, p<0.002)$, and MSP10 $(\mathrm{r}=-0.93$, $p<0.007)$. For WSP100, WSP72, WSP35, and MSP52, the low number of tests and the small 
range of $\lambda$ values tested make it impossible to draw conclusions. If all the fuels are analysed together (44 tests with $\lambda>1)$, a clear correlation between $\lambda$ and $\mathrm{T}_{\text {if }}$ is obtained $(\mathrm{r}=-0.59$, $p<0.001)$.

In general, the fuels showed similar behaviour in a wide range of primary air conditions, following the three regimens explained in previous sections. Table 8 summarizes the main features of the tests performed.

Table 8. Summary of reactor tests features.

\begin{tabular}{cccccccccc}
\hline & & WP100 & WSP100 & WSP72 & WSP60 & WSP35 & MSP100 & MSP52 & MSP10 \\
\hline \multicolumn{2}{r}{ Number of successful tests } & 10 & 8 & 8 & 9 & 10 & 5 & 8 & 10 \\
\hline & Min & 0.66 & 0.85 & 0.75 & 0.74 & 0.62 & 0.81 & 0.64 \\
$\lambda$ & Max & 1.91 & 1.67 & 1.35 & 1.41 & 1.48 & 1.18 & 1.27 & 1.64 \\
& Mean & 1.20 & 1.12 & 1.04 & 1.08 & 1.06 & 0.98 & 0.93 & 1.04 \\
$\mathbf{T}_{\mathbf{i f}}$ & Min & 934.9 & 1134.7 & 1103.3 & 1009.2 & 1099.6 & 1234.1 & 1202.6 & 1151.6 \\
$\left({ }^{\circ} \mathbf{C}\right)$ & Max & 1179.5 & 1251.7 & 1168.9 & 1136.1 & 1239.4 & 1267.6 & 1281.9 & 1267.6 \\
& Mean & 1069.0 & 1176.4 & 1133.3 & 1090.6 & 1180.5 & 1248.0 & 1235.2 & 1229.6 \\
\hline
\end{tabular}

\subsection{Bottom Ash}

In this section, the variation for the different fuels of bottom ash proportion, the ash that remains in the grate with respect to the one fed, as well as their sintering degree will be shown. The sintering degree of bottom ash is key to analyse the behaviour of the fuel, due to the problems that these structures can generate during the combustion and for the equipment. First, the influence of the operating conditions on both values will be analysed and then the results obtained between fuels will be compared.

\subsubsection{Influence of Operating Conditions}

Figures 6 and 7 show sintering degree of bottom ash as a function of $\lambda$ for the WSP and MSP family, respectively.

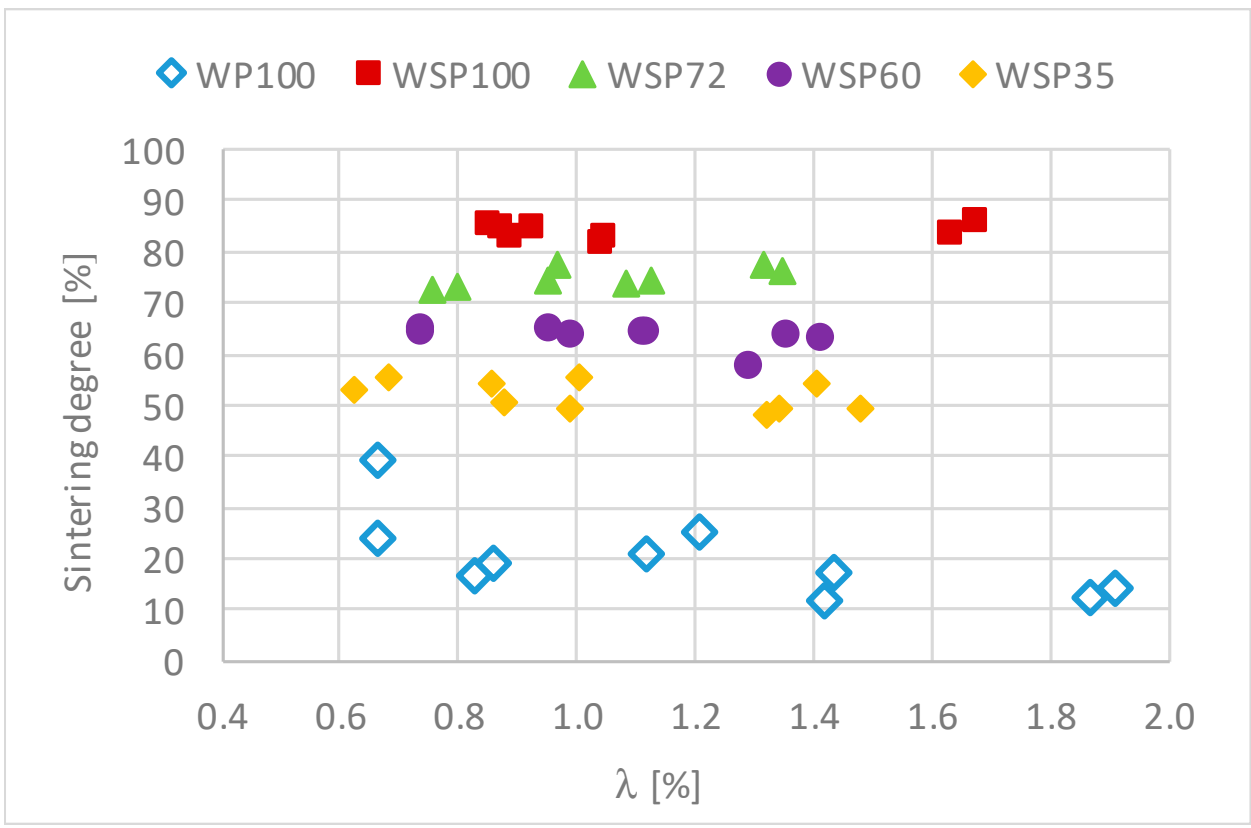

Figure 6. Sintering degree versus $\lambda$ for the WP100 and WSP family. 


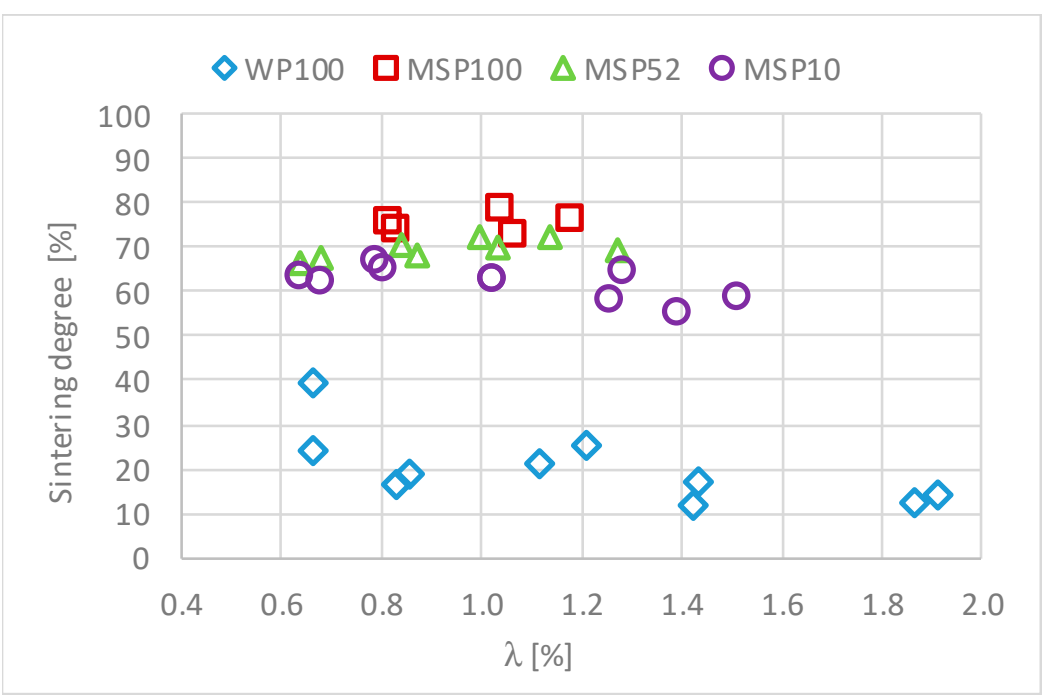

Figure 7. Sintering degree versus $\lambda$ for the WP100 and MSP family.

For WP100, the sintering degree decreases with $\lambda(\mathrm{r}=-0.67, p=0.032)$ because the combustion temperature decreases also (see Figure 5). It should be noted that the values are significantly higher in tests with lower $\lambda$, which is consistent with the strangely high temperatures obtained in these tests. Agropellets present a significantly higher sintering degree than WP100, even with small percentages of herbaceous (MSP10), in line with the lower values of ash fusibility temperatures presented by these fuels (see Table 2). Furthermore, it was not possible to find a correlation between the sintering degree and $\lambda$. Due to tests being performed with $\lambda$ values greater and less than 1 , the temperature variation was small, especially for MSP family tests (see Figure 5 or Table 3), which caused a lesser sintering degree variation than what had been detected in similar experiences with blended pellets [44].

Regarding the bottom ash proportion with respect to the total amount of ash fed with the fuel, Figures 8 and 9 show the relationship of this parameter with $\lambda$ for the WP100 and for each of the two fuel families (WSP family and MSP family). WP100 has a lower bottom ash share than the rest of the fuels and decreases when $\lambda$ increases $(\mathrm{r}=-0.71, p=0.021)$. These two facts can be indicative of a great entrainment of solid particles on this fuel, due to the low sintering degree that it presents that, in addition, decreases with $\lambda$ (see Figure 6).

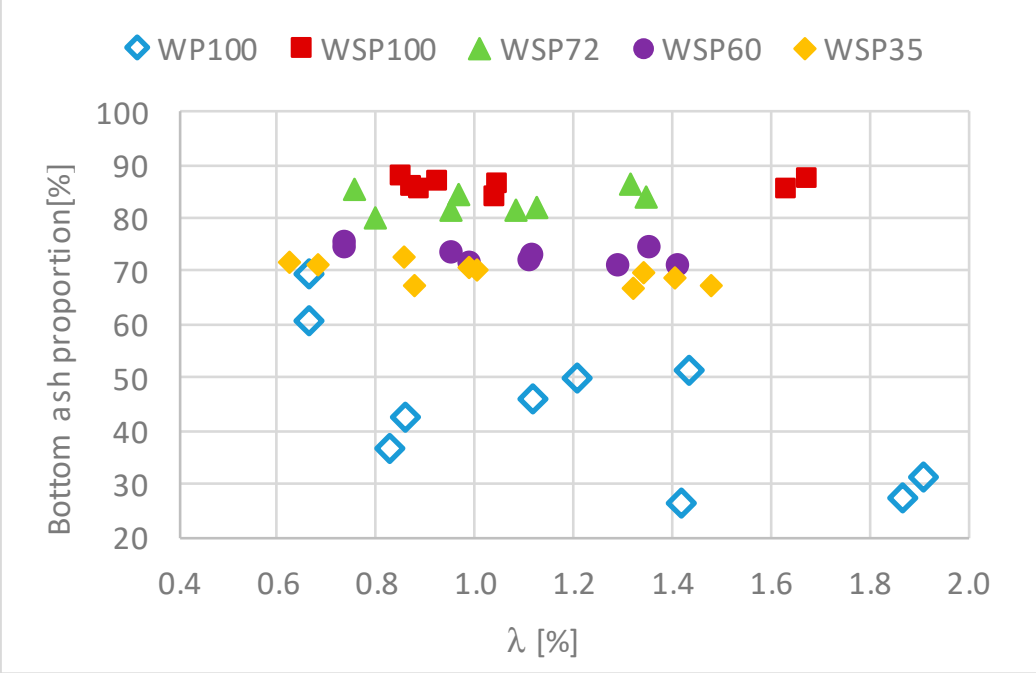

Figure 8. Bottom ash proportion (\% with respect to the total amount of ash introduced with the fuel) versus $\lambda$ for the WP100 and WSP family. 


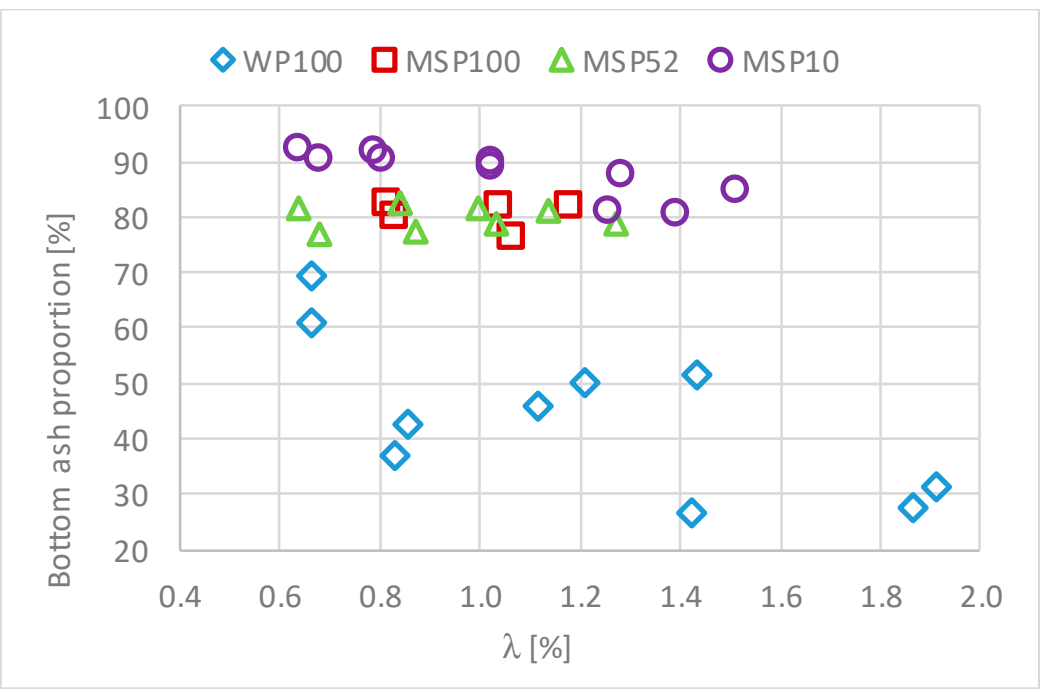

Figure 9. Bottom ash proportion (\% with respect to the total amount of ash introduced with the fuel) versus $\lambda$ for the WP100 and MSP family.

For agropellets, the relationship between bottom ash proportion and $\lambda$ is less clear, varying only slightly. On the one hand, the temperature barely varies, which means that the vaporization does not either. On the other hand, the high sintering degree presented by these fuels prevents an increase of the entrainment of solid particles. These effects will have to be confirmed by means of the assessment of the SEM-EDS and XRD analyses results that will be carried out in [53].

\subsubsection{Comparison between Fuels}

Comparing the behaviour between the two families of agropellets, it can be seen (Figures 6 and 7) that in both cases the sintering degree clearly increases as the percentage of herbaceous increases. This fact is more evident in the case of the WSP family. However, it is important to remark that a greater percentage of wood in the blend does not imply a proportional decrease in the sintering degree. Therefore, it could be interesting to find the most suitable replacement percentage for each blend in order to increase as much as possible the use of herbaceous biomass while guaranteeing good performance during the combustion. The WSP family presents a slightly lower sintering degree than the MSP family, but only in the blended pellets, since pure herbaceous fuels WSP100 has a greater tendency to sinter ( $>80 \%$ in WSP100 and $<80 \%$ in MSP100).

Since a clear influence of $\lambda$ on the amount of bottom ash or on its sintering degree has not been found, except in the case of the WP100, it may be interesting to work with mean values to facilitate this analysis. Table 9 shows the average values of sintering degree and the bottom ash proportion of the tests performed with each fuel. The different behaviour of the WP100 compared to agropellets is remarkable. It can be seen how, while for the WP100 less than $50 \%$ of the bottom ash has a high sintering status, in all agropellets the similarity between the bottom ash proportion and the sintering degree is much higher, so that in WSP100 and MSP100 both values practically are equal—all the bottom ash is sintered and the $\mathrm{S} 1$ fraction is negligible. Therefore, there is more bottom ash, and it is more sintered. 
Table 9. Bottom ash proportion and sintering degree obtained with each fuel (mean of all tests).

\begin{tabular}{ccccccccc}
\hline & WP100 & WSP100 & WSP72 & WSP60 & WSP35 & MSP100 & MSP52 & MSP10 \\
\hline Bottom ash proportion (\%) & 44.21 & 86.21 & 83.18 & 72.65 & 69.59 & 80.65 & 79.94 & 87.95 \\
\hline Sintering degree (\%) & 19.96 & 84.15 & 74.86 & 63.09 & 51.88 & 75.51 & 69.56 & 62.07 \\
\hline $\begin{array}{c}\text { Total bottom ash collected } \\
\text { (kg/MJ) (a) }\end{array}$ & 0.23 & 3.12 & 1.82 & 1.24 & 1.56 & 6.55 & 2.80 & 1.52 \\
\hline
\end{tabular}

(a) Calculated on LHV (d.b.).

There is an additional problem, since agropellets present a higher percentage of ash than woody pellet, which means that the absolute amount of ash that is retained in the bed is also significantly higher. As shown in Table 9, the amount of ash collected per unit of energy in the cases of the WSP100 and the MSP100 is almost 14 and above-28 times more than in the WP100, respectively. Therefore, the management of the ash can be challenging if there is not an adequate cleaning system. These differences decrease as wood percentage in the blend increases, which justifies the need to use blends to solve not only ash quality problems, but also quantity, contributing to increasing the use of herbaceous fuels for energy purposes.

Regarding the influence of the fuel composition on sintering problems, Figures 10-12 show the relationships between the ash elements (shown as oxides, Table 3 ) that participate more actively in the sintering phenomenon $\left(\mathrm{SiO}_{2}, \mathrm{~K}_{2} \mathrm{O}+\mathrm{Na}_{2} \mathrm{O}, \mathrm{CaO}+\mathrm{MgO}\right)$ and the mean value of sintering degree for each fuel (Table 7). As previous experiences showed $[29,54]$, there is a clear direct correlation between the sintering degree and the content of $\mathrm{SiO}_{2}$ in the fuel ash (Figure 10: $\mathrm{r}=0.88, p=0.004$ ). Si in the presence of alkali metals, mainly $\mathrm{K}$, gives rise to alkali silicates that have a low melting temperature and contribute to increase sintering problems [40]. At the bottom end is the WP100, which has the lowest $\mathrm{SiO}_{2}$ content and the lowest sintering degree. In the case of the WSP family, the $\mathrm{SiO}_{2}$ content increases with the percentage of herbaceous, which implies a progressive increase in sintering degree. For the MSP family, the similarities between the composition of fuels (as previously mentioned in Section 2.1) implies that the relationship between the two parameters is not so clear. Even so, MSP10 does have the lowest $\mathrm{SiO}_{2}$ content and the lowest sintering tendency. It should be noted that all the agropellets present a $\mathrm{SiO}_{2}$ percentage higher than $20 \%$, which led to foreseeing sintering problems [28] as the tests have shown. Due to the high $\mathrm{SiO}_{2}$ content of the raw materials as well as its ash percentage, any amount of herbaceous in the blend implies that the problematic threshold is exceeded.

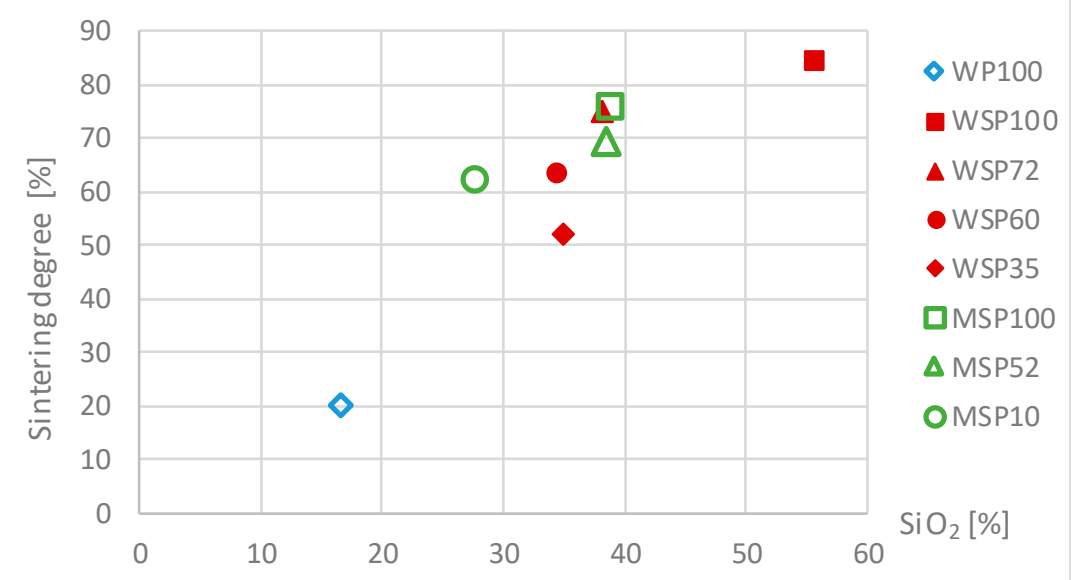

Figure 10. Mean sintering degree of bottom ash versus $\mathrm{SiO}_{2}$ concentration in fuel preliminary analysis (Table 3) for each fuel. 


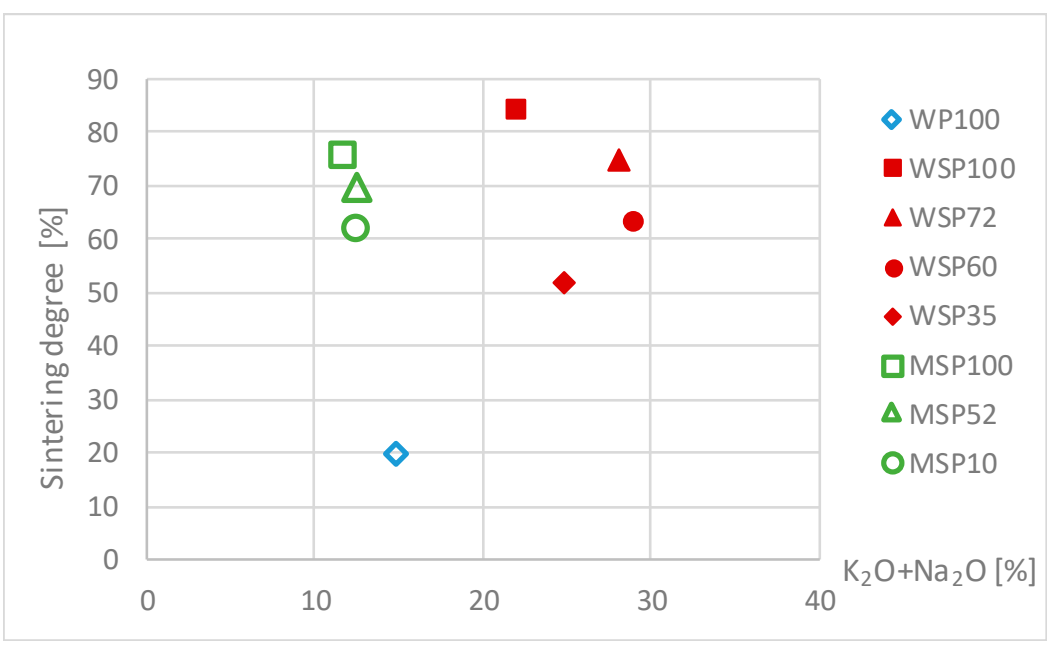

Figure 11. Mean sintering degree of bottom ash versus $\mathrm{K}_{2} \mathrm{O}+\mathrm{Na}_{2} \mathrm{O}$ concentration in fuel preliminary analysis (Table 3) for each fuel.

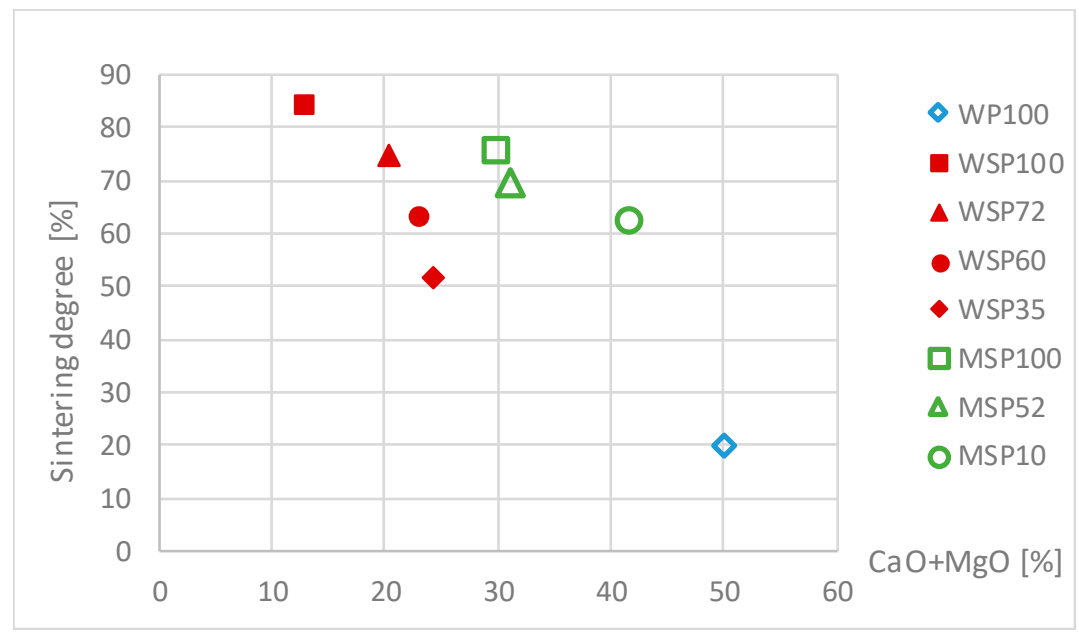

Figure 12. Mean sintering degree of bottom ash versus $\mathrm{CaO}+\mathrm{MgO}$ concentration in fuel preliminary analysis (Table 3) for each fuel.

Nevertheless, from Figure 11 it is not possible to draw conclusions about the influence of the content of $\mathrm{K}_{2} \mathrm{O}+\mathrm{Na}_{2} \mathrm{O}$ (the existence of a correlation between these elements and sintering degree cannot be stated: $\mathrm{r}=0.16, p=0.709$ ), which seems to indicate that, given the high content of these compounds in the fuels tested, the limiting factor for the formation of the aforementioned alkali silicates is $\mathrm{Si}$.

On the other hand, there is an inverse correlation with the content of $\mathrm{CaO}+\mathrm{MgO}$ (Figure 12: $\mathrm{r}=-0.77, p=0.025$ ), since alkaline earth metals contribute to the formation of compounds with a higher melting temperature, decreasing the tendency of fuels to sinter $[27,38]$.

The sintering degree does not statistically correlate with the ratio $(\mathrm{Si}+\mathrm{P}+\mathrm{K}+$ $\mathrm{Na}) /(\mathrm{Ca}+\mathrm{Mg}$ ) (Figure 13a; $\mathrm{r}=0.64, p=0.322$ ) or SST (Figure 13b; $r=0.19, p=0.677$ ), mainly due to the displacement that the MSP family presents towards a much higher degree of sintering than expected according to the values of these two parameters. This could be due, at least to some extent, to the fact that in these tests $T_{\text {if }}$ was significantly higher than the values achieved when testing the remaining fuels (see Table 8), exceeding their SST. Nevertheless, there is not enough information to know with certainty if these higher values of $T_{\text {if }}$ are the only reason causing these higher sintering degrees. What seems clear is that the difference between the combustion temperatures obtained for each fuel is 
related to its intrinsic characteristics, since the operating parameters used in the tests $(\lambda$ and air temperature) are similar for all of them (see Table 8 and Figure 5).
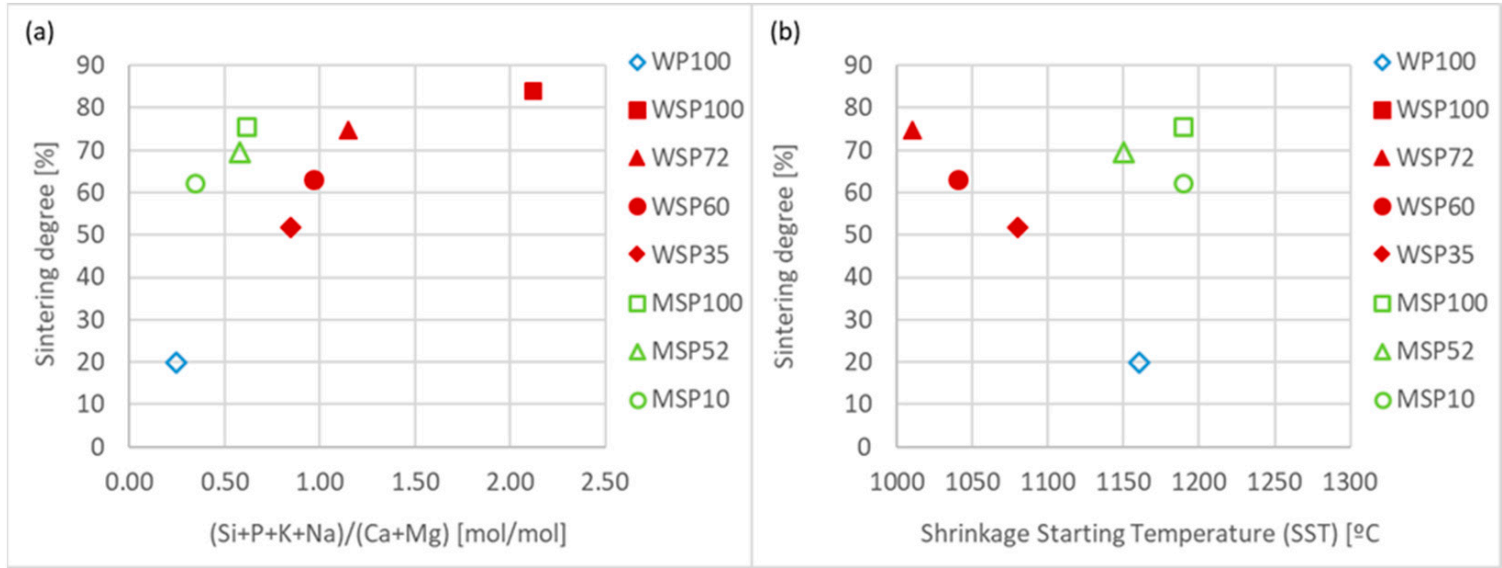

Figure 13. (a) Mean sintering degree of the bottom ash versus ratio $(\mathrm{Si}+\mathrm{P}+\mathrm{K}+\mathrm{Na}) /(\mathrm{Ca}+\mathrm{Mg})$; (b) Mean sintering degree of the bottom ash versus fuel shrinkage starting temperature (SST).

On the other hand, when trying to relate the sintering degree with the values obtained for the selected indices (Table 6), no clear correlations are found, which is in accordance with what has been obtained in other research works, where the utility of indices to predict the performance of biomass fuels is questioned (e.g., [42,47,55-57]). Nevertheless, a good relationship has been found between the sintering trends marked by the Sr index according to the new thresholds defined in [38] and the results obtained in the tests for fuels sintering degree (see Figure 14, $\mathrm{r}=0.84, p=0.009$ ).

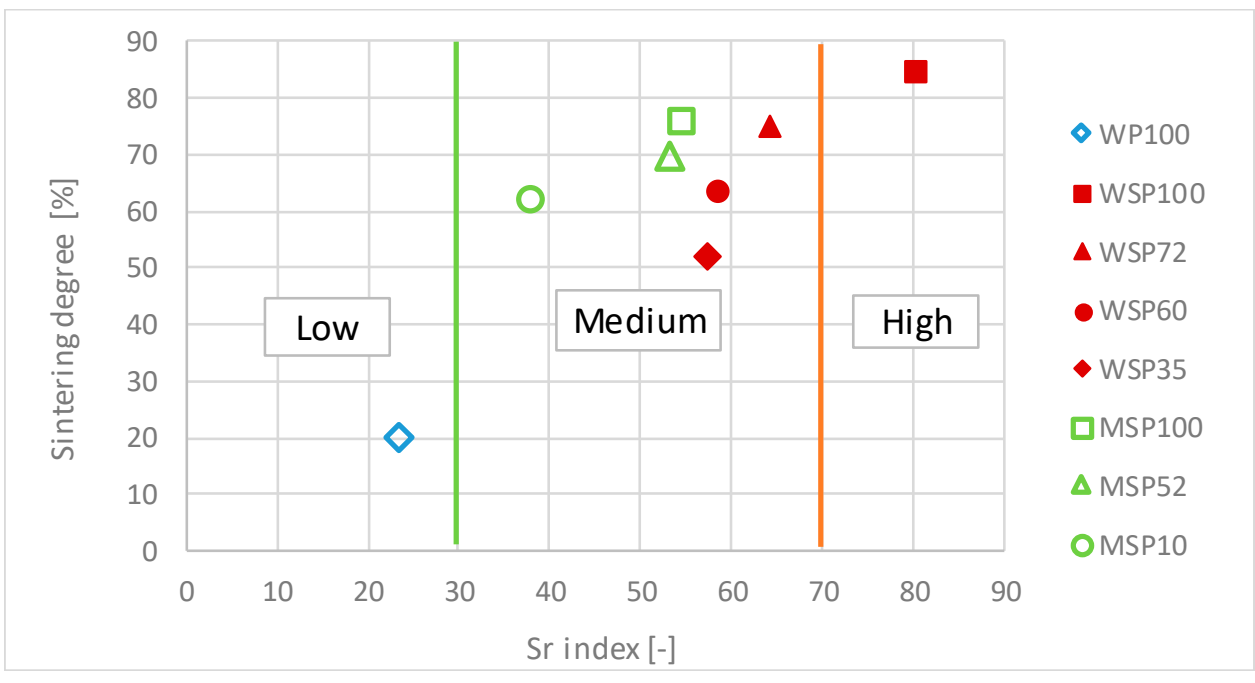

Figure 14. Mean sintering degree of the bottom ash versus Sr index.

At the two extremes are WSP100, which is the one with the highest sintering degree, with a Sr value above 70 (high sintering tendency) and WP100 with the lowest degree and a value below 30 (low sintering tendency). In the intermediate zone the rest of the fuels have, compared to the other two, shown an intermediate sintering degree and a value of Sr that predicted this behaviour. It is worth noting that, although in this case the MSP family is displaced towards higher values of sintering degree with respect to the other fuels, this index allows us to predict its behaviour better than the SST (Figure 13b). Finally, it should be highlighted that, as can be seen in Table 6, if the prediction of traditional limits for this index had been used, the results would have been totally different. Hence, this result confirms the need to adapt not only the indices but the limits also, to the specific 
characteristics of the biomass, since in most cases they were defined to predict the behaviour of coal.

Therefore, it can be stated that some molar ratios and indices, as well as melting temperatures, are a good starting point for estimating the sintering problems of a fuel, but they cannot adequately predict by themselves the behaviour under real conditions [32,34], among other reasons because they do not take into account the particular combustion conditions (mainly temperature) of each fuel.

\subsection{Deposition}

There are two ways in which ash can leave the bed: vaporization and entrainment. Each of them leads to a different deposition mechanism, one produced by condensation (including thermophoresis and turbulent diffusion) and another by inertial impact, respectively. From the deposition rate (DR), the total quantity of ash that is deposited by these mechanisms in the boiler tubes can be estimated. The ash produced could cause problems such as decreased heat transfer, erosion, or corrosion, which would decrease the boiler efficiency as well as its useful life.

From the tests carried out, it has been possible to determine DR for several values of $\lambda$ for each fuel (only for $\lambda>1$; Figures 15 and 16).

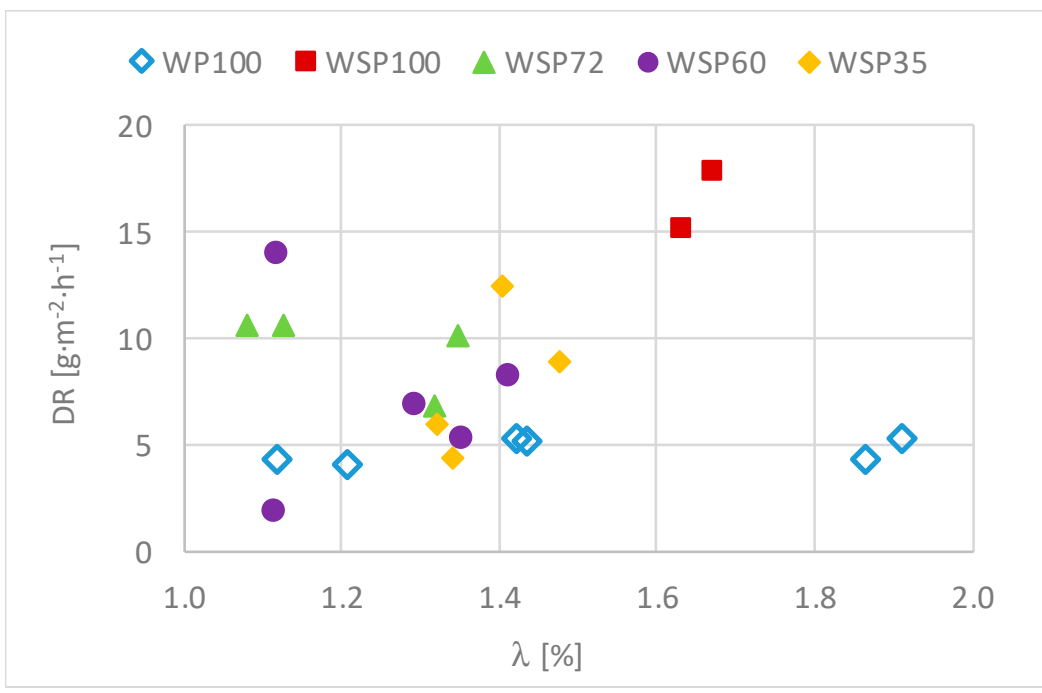

Figure 15. Deposition rate (DR) versus $\lambda$ for the WP100 and WSP family.

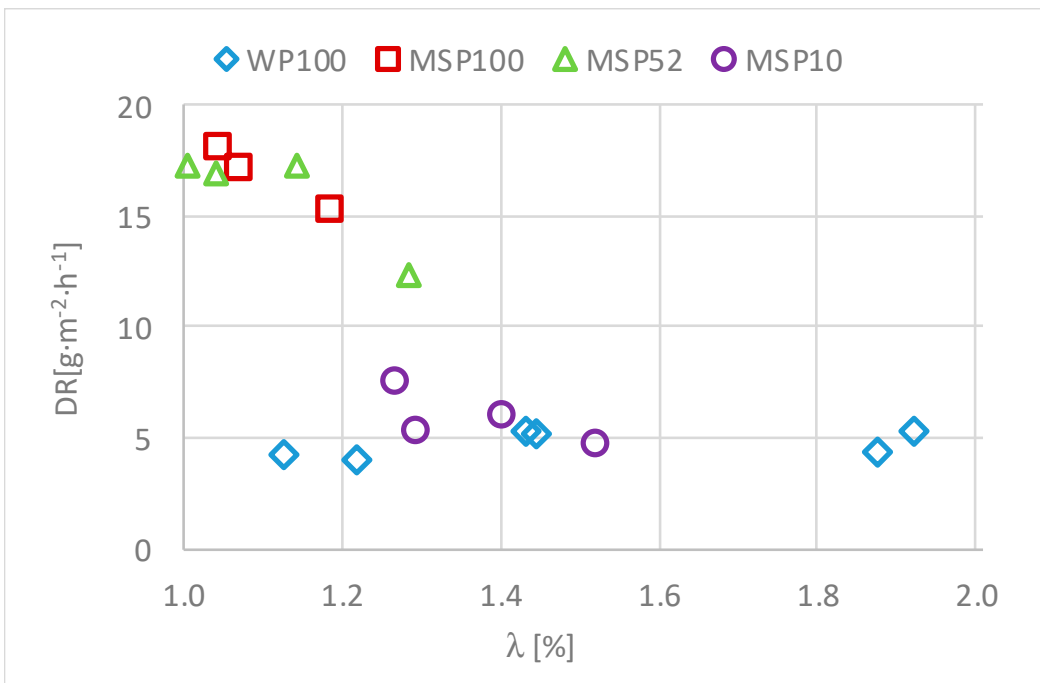

Figure 16. Deposition rate (DR) versus $\lambda$ for the WP100 and MSP family. 
It should be noted that, in general, the DR values for the WP100 are lower than the ones obtained for the blended pellets. This result was predictable, taking into account the percentage of ash of the fuel and their composition (lower K content than the WSP family, lower $\mathrm{Cl}$ content than the MSP family, except MSP10, and the lowest S content), which is in agreement with those obtained for other similar fuels in the same reactor [44].

Regarding the variation of DR with $\lambda$, due to the low number of tests for each fuel, it is not possible to obtain statistically significant correlations for each of them, except in the case of WP100 (for which DR remains practically constant in values of the order of $5 \mathrm{~g} \cdot \mathrm{m}^{-2} \cdot \mathrm{h}^{-1}$ ) and MSP10 (for which DR decreases with $\lambda ; \mathrm{r}=-0.92, p=0.010$ ). Given the scarcity of data by fuel, it is interesting to analyse all of them together (33 tests between the 8 fuels). In this way, an inverse correlation between DR and $\lambda$ is obtained $(\mathrm{r}=-0.34$; $p=0.051$ ). Although this correlation is not statistically significant, the $p$ value close to 0.05 suggests that there is a certain relationship between the deposition phenomenon and $\lambda$, although there are other factors that affect it, among them, of course, the composition of the fuel.

However, in order to analyse both the influence of the composition of the fuels and the operating conditions in-depth, it is necessary to distinguish between the two mentioned deposition mechanisms which will be done, based on the results of the SEM-EDS analysis [10], that will be presented in [53].

As has already been done for sintering phenomenon, relationships between index values (Table 7) and mean deposition rates obtained (presented in Table 10) have been analysed.

Table 10. Mean values of $D R, \lambda$, and $T_{\text {if }}$ for each fuel in the test with $\lambda>1$.

\begin{tabular}{ccccccccc}
\hline & WP100 & WSP100 & WSP72 & WSP60 & WSP35 & MSP100 & MSP52 & MSP10 \\
\hline $\mathbf{D R}\left(\mathbf{g} \cdot \mathbf{m}^{-\mathbf{2}} \cdot \mathbf{h}^{-\mathbf{1}}\right)$ & 4.71 & 16.49 & 9.53 & 7.18 & 8.53 & 16.90 & 15.97 & 5.87 \\
\hline $\boldsymbol{\lambda}$ & 1.49 & 1.35 & 1.22 & 1.36 & 1.31 & 1.26 & 1.11 & 1.25 \\
\hline $\mathbf{T}_{\mathbf{i f}}\left({ }^{\circ} \mathbf{C}\right)$ & 1022 & 1200 & 1135 & 1053 & 1166 & 1234 & 1235 & 1217 \\
\hline
\end{tabular}

In the case of the $\mathrm{Fu}$ index, a prediction opposite to the experimental results has been obtained, mainly because this index does not include the percentage of fuel ash that obviously directly influences DR. Nevertheless, DR has a direct correlation with AI index value (Figure 17, $\mathrm{r}=0.77, p=0.025$ ). According to the reference values set for this index [37,40], WP100 was the only fuel in which deposition problems were not foreseeable $\left(\mathrm{Al}<0.17 \mathrm{~kg}_{\text {alkali }} / \mathrm{GJ}\right)$, which coincides with the experimental result obtained for this fuel. All the blended pellets would present a high risk of deposition (AI $\left.>0.34 \mathrm{~kg}_{\text {alkali }} / \mathrm{GJ}\right)$ except for MSP10 which, once again confirming the experimental result, would remain in the intermediate zone. The results obtained, therefore, coincide with the forecasts made.

Although the relationship between both parameters is statistically representative, it does not present a very low $p$-value, which seems to indicate that there could be other influencing factors. In this sense, among the agropellets that present an AI value $>0.34 \mathrm{~kg}_{\text {alkali }} / \mathrm{GJ}$, two groups of fuels can be differentiated based on the DR obtained for each one, which is closely related to higher or lower real deposition occurrence. Those with a higher DR (upper part of the figure, MSP52, WSP100, and MSP100) are related to tests in which the combustion temperature was higher (above $1200^{\circ} \mathrm{C}$, see Table 8), which could increase the vaporization phenomenon associated with higher deposition problems. This fact reinforces the conclusion already pointed out when analysing sintering tendency concerning the limitations of the indices, which do not allow consideration of the combustion conditions when assessing the final behaviour of the fuel. 


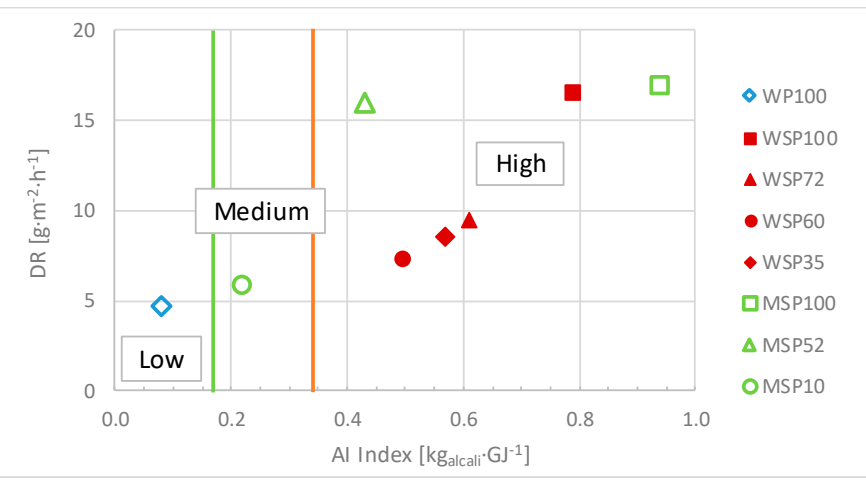

Figure 17. AI index versus average deposition rate for each fuel.

\section{Conclusions}

In this paper, the behaviour in combustion of seven agropellets (two pure, wheat straw and maize stalk, and five blends of these herbaceous with a forestry wood) has been analysed and compared with that of a 100\% forestry woody pellet (reference fuel). All of them were produced in a IBCL and complied with ISO 17225-6 class A or B.

From the composition of the fuels, various ratios and indices were calculated, which, together with their ash fusibility temperatures, were used to try to predict the behaviour of fuels with respect to sintering and deposition. Because these predictions presented conflicting results, experimental tests have served both to confirm the real behaviour of the fuels and to verify the usefulness of these indices.

When comparing the performance during combustion of agropellets with the reference fuel, the main drawback was related to sintering and deposition problems associated with the ash. It can also be verified that, in general, the higher the percentage of herbaceous material in the blend, the higher the sintering degree and bottom ash proportion is (in the MSP family this trend it is not so clear, which is directly related to similar fuel composition). However, it is important to remark that over a certain amount, an increase of the wood content in the blend does not clearly imply a higher quality of the final blend.

It has been confirmed that, given the high percentage of $\mathrm{K}$ in all fuels, there are clear correlations between the sintering degree and $\mathrm{Si}$ (direct), as well as $\mathrm{Ca}+\mathrm{Mg}$ (indirect) percentages. However, it has been found that the combustion temperature also has a very significant influence on sintering occurrence. Thus, for example, its high value in the case of the MSP family causes a greater sintering than would be expected when considering its composition.

Thus, it can be concluded that the combustion conditions also affect the behaviour of the bottom ash, so that the prediction of the behaviour of a fuel only from its composition and analysis (indices) is not always accurate and boiler operating conditions should be adapted in order to diminish ash-related problems.

Regarding deposition, as expected considering its lower content in $\mathrm{K}, \mathrm{Cl}$, and $\mathrm{S}$, the woody pellet has presented a significantly lower DR compared to agropellets. However, due to the high number of factors involved in this phenomenon and the few data available, it has not been possible to draw conclusions about the influence of combustion conditions.

It has been proven that the IBLC concept is suitable for pellet production given that these agropellets have similar characteristics compared to commercial ones, and they present adequate combustion parameters $\left(\mathrm{m}_{\mathrm{ir}}\right.$ and $\left.\mathrm{T}_{\mathrm{if}}\right)$ for a wide range of excess air (especially the blended pellets). However, it is necessary to have a more in-depth understanding of its behaviour in terms of the sintering degree and DR to try to minimize its negative effects and thus be able to increase the penetration in the market of these fuels. This deepening is the main objective of the second part of this work [53].

Author Contributions: Conceptualization, S.Z., M.G., C.B., P.C. and J.R.; methodology, S.Z., P.C and J.R.; experimentation and validation, S.Z., P.C. and J.R.; formal analysis, S.Z., M.G., C.B., P.C. 
and J.R.; writing-original draft preparation, review and editing S.Z., M.G., C.B., P.C. and J.R.; visualization and supervision, S.Z., M.G., C.B., P.C. and J.R.; project administration, S.Z., M.G. and C.B.; funding acquisition, S.Z., M.G. and C.B. All authors have read and agreed to the published version of the manuscript.

Funding: This publication is part of a project that has received funding from the European Union's Horizon 2020 research and innovation programme under grant agreement No 727961. The work was performed in the framework of the European project AGROinLOG (Grant Agreement No 727961) "Demonstration of innovative integrated biomass logistics centres for the Agro-industry sector in Europe". www.agroinlog-h2020.eu (accessed on 28 December 2021). Authors would also like to thank the Government of Aragon in Spain for partial funding of this publication.
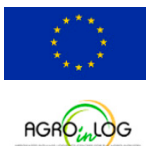

Institutional Review Board Statement: Not applicable.

Informed Consent Statement: Not applicable.

Data Availability Statement: Not applicable.

Acknowledgments: We would like to acknowledge Bárbara Palacino, Javier Marcos and Óscar Puyo for their support during experimental work.

Conflicts of Interest: The authors declare no conflict of interest.

\section{Abbreviations}

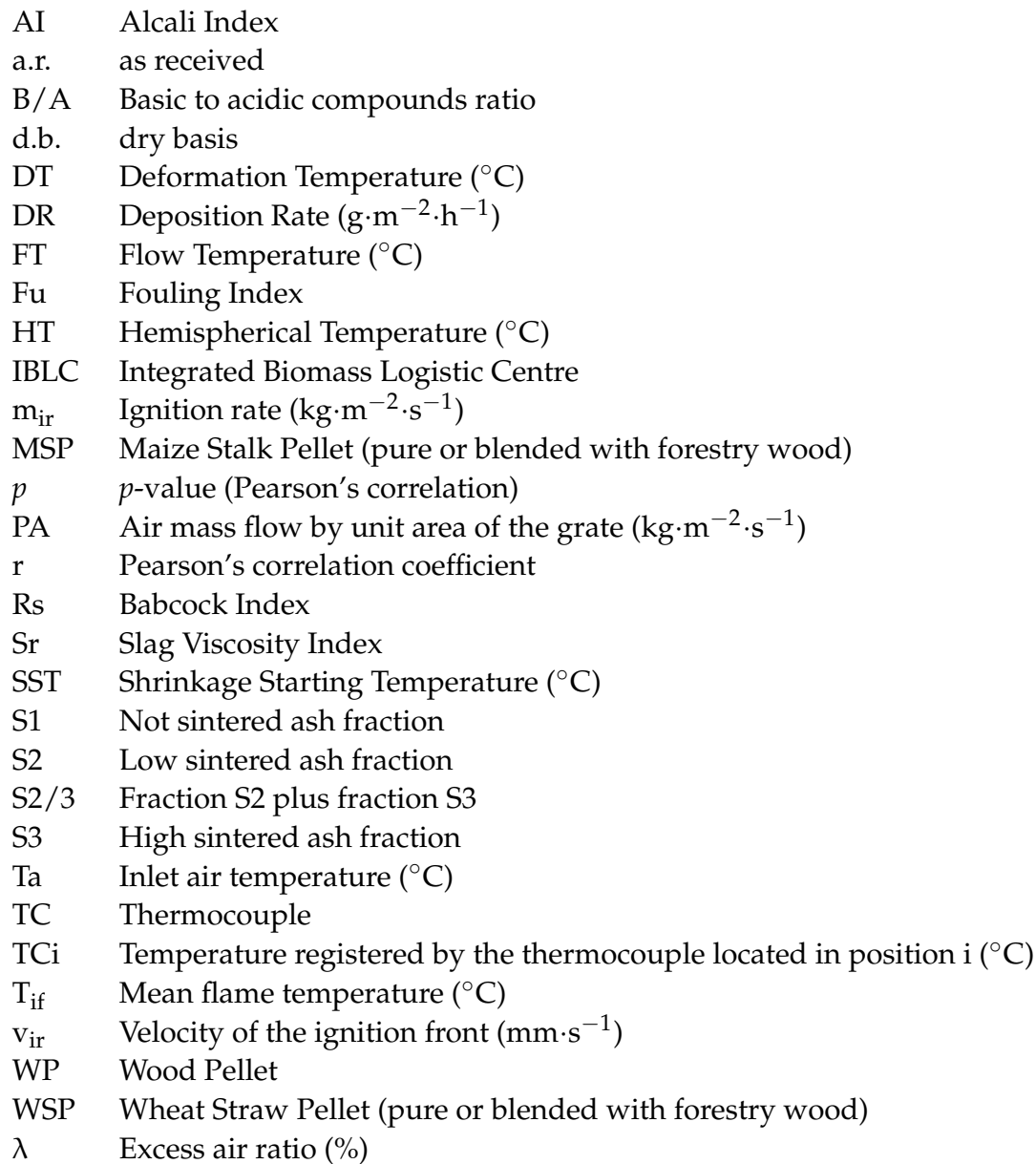




\section{References}

1. Website European Project Agroinlog. Demonstration of Innovative Integrated Biomass Logistics Centres for the Agro-Industry Sector in Europe. Available online: http:/ /agroinlog-h2020.eu/en/home/ (accessed on 17 February 2021).

2. Swedish University of Agriculture Science (SLU). D5.1 A Report on Logistics Chain and Knowledge Gaps of Biomass; Europruning project (Grant Agreement No 312078); Swedish University of Agriculture Science: Uppsala, Sweden, 2016.

3. Poutrin, C.; Dzene, I.; López, E.; Engelmann, K. Handbook for Agro-Industries Interested in Starting a New Activity as Biomass Logistic Centre: Lessons Learned and Good Practice Examples; Sucellog project (No EE-13-638-SI2_675535); European Union: Maastricht, The Netherlands, 2016.

4. Poutrin, C.; Engelmann, K. Handbook for Agro-Industries Interested in Starting a New Activity as Biomass Logistic Centre: Carrying out a Feasibility Study; Sucellog project (No EE-13-638-SI2_675535); European Union: Maastricht, The Netherlands, 2016.

5. Practitioners Guidebook. BioRES-Sustainable Regional Supply Chains for Woody Bioenergy Project (Grant Agreement No 645994). 2017. Available online: http:/ / bioresproject.eu/wp-content/uploads/2017/09/D8.7-Practitioners-guidebook.pdf (accessed on 15 August 2020).

6. Final Report. Vineyards for Carbon Footprint Reduction: A Sustainable Strategy to Use Biomass for Heat\&Cold in Wineries Project (No LIFE13 ENV/ES/00076). 2017. Available online: http://vineyards4heat.eu/wp-content/uploads/2017/11/Final_ Technical_report_V4H.pdf (accessed on 10 September 2021).

7. Scarlat, N.; Dallemand, J.-F.; Monforti-Ferrario, F.; Banja, M.; Motola, V. Renewable energy policy framework and bioenergy contribution in the European Union-An overview from National Renewable Energy Action Plans and Progress Reports. Renew. Sustain. Energy Rev. 2015, 51, 969-985. [CrossRef]

8. Scarlat, N.; Dallemand, J.-F.; Monforti-Ferrario, F.; Nita, V. The role of biomass and bioenergy in a future bioeconomy: Policies and facts. Environ. Dev. 2015, 15, 3-34. [CrossRef]

9. van Loo, S.; Koppejan, J. The Handbook of Biomass Combustion and Co-Firing; Earthscan: London, UK, 2012.

10. Royo, J.; Canalís, P.; Quintana, D. Chemical study of fly ash deposition in combustion of pelletized residual agricultural biomass. Fuel 2020, 268, 117-228. [CrossRef]

11. Glarborg, P.; Marshall, P. Mechanism and modeling of the formation of gaseous alkali sulfates. Combust. Flame 2005, 141, 22-39. [CrossRef]

12. Garba, M.U.; Ingham, D.B.; Ma, L.; Porter, R.T.J.; Pourkashnian, M.; Tan, H.Z.; Williams, A. Prediction of Potassium Chloride Sulfation and Its Effect on Deposition in Biomass-Fired Boilers. Energy Fuels 2012, 26, 6501-6508. [CrossRef]

13. Sengeløv, L.; Hansen, T.; Bartolomé, C.; Wu, H.; Pedersen, K.H.; Frandsen, F.J.; Jensen, A.D.; Glarborg, P. Sulfation of Condensed Potassium Chloride by $\mathrm{SO}_{2}$. Energy Fuels 2013, 27, 3283-3289. [CrossRef]

14. ISO 17225-6:2014; Solid Biofuels-Fuel Specifications and Classes-Part 6: Graded Non-Woody Pellets. The National Standards Authority of Ireland: Dublin, Ireland, 2014. Available online: https://www.iso.org/standard/59461.html(accessed on 10 September 2021).

15. Zapata, S.; Gomez, M.; Postolache, S.; Serrat, C. D3.7 Success Case of an IBLC into an Agroindustry of the Animal Feed Sector. AGROINLOG Project No 727161. Available online: http:/ / agroinlog-h2020.eu/es/2019/05/21/d3-7_caso-exito-la-integracioncentro-logistico-una-agroindustria-del-sector-la-alimentacion-animal/ (accessed on 10 September 2021).

16. Díaz-Ramírez, M.; Sebastian, F.; Royo, J.; Rezeau, A. Influencing factors on NOX emission level during grate conversion of three pelletized energy crops. Appl. Energy 2014, 115, 360-373. [CrossRef]

17. Johansson, L.S.; Leckner, B.; Gustavsson, L.; Cooper, D.; Tullin, C.; Potter, A. Emission characteristics of modern and old-type residential boilers fired with wood logs and wood pellets. Atmos. Environ. 2004, 38, 4183-4195. [CrossRef]

18. Obernberger, I.; Biedermann, F.; Widmann, W.; Riedl, R. Concentrations of inorganic elements in biomass fuels and recovery in the different ash fractions. Biomass Bioenergy 1997, 12, 211-224. [CrossRef]

19. Wierzbicka, A.; Lillieblad, L.; Pagels, J.; Strand, M.; Gudmundsson, A.; Gharibi, A.; Swietlicki, E.; Sanati, M.; Bohgard, M. Particle emissions from district heating units operating on three commonly used biofuels. Atmos. Environ. 2005, 39, 139-150. [CrossRef]

20. Wiinikka, H.; Gebart, R.; Boman, C.; Boström, D.; Öhman, M. Influence of fuel ash composition on high temperature aerosol formation in fixed bed combustion of woody biomass pellets. Fuel 2007, 86, 181-193. [CrossRef]

21. Wiinikka, H.; Gebart, R. Experimental investigations of the influence from different operating conditions on the particle emissions from a small-scale pellets combustor. Biomass Bioenergy 2004, 27, 645-652. [CrossRef]

22. Brunner, T.; Obernberger, I.; Scharler, R. Primary measures for low-emission residential wood combustion-Comparison of old with optimised modern systems. In Proceedings of the 17th European Biomass Conference and Exhibition, Hamburg, Germany, 29 June-3 July 2009; pp. 1319-1328.

23. Obernberger, I.; Brunner, T.; Bärnthaler, G. Chemical properties of solid biofuels-significance and impact. Biomass Bioenergy 2006, 30, 973-982. [CrossRef]

24. Díaz-Ramírez, M.; Boman, C.; Sebastian, F.; Royo, J.; Xiong, S.; Boström, D. Ash Characterization and Transformation Behavior of the Fixed-Bed Combustion of Novel Crops: Poplar, Brassica, and Cassava Fuels. Energy Fuels 2012, 26, 3218-3229. [CrossRef]

25. Díaz-Ramírez, M.; Sebastian, F.; Royo, J.; Rezeau, A. Combustion requirements for conversion of ash-rich novel energy crops in a $250 \mathrm{kWthmultifuel} \mathrm{grate} \mathrm{fired} \mathrm{system.} \mathrm{Energy} \mathrm{2012,} \mathrm{46,} \mathrm{636-643.} \mathrm{[CrossRef]}$

26. Díaz-Ramírez, M.; Frandsen, F.J.; Glarborg, P.; Sebastian, F.; Royo, J. Partitioning of K, Cl, S and P during combustion of poplar and brassica energy crops. Fuel 2014, 134, 209-219. [CrossRef] 
27. Boström, D.; Skoglund, N.; Grimm, A.; Boman, C.; Öhman, M.; Broström, M.; Backman, R. Ash Transformation Chemistry during Combustion of Biomass. Energy Fuels 2012, 26, 85-93. [CrossRef]

28. Öhman, M.; Nordin, A.; Hedman, H.; Jirjis, R. Reason for slagging during stemwood pellet combustion and some measures for prevention. Biomass Bioenergy 2004, 27, 597-605. [CrossRef]

29. Royo, J.; Canalís, P.; Quintana, D. Chemical study of bottom ash sintering in combustion of pelletized residual agricultural biomass. Fuel 2022, 310, 122145. [CrossRef]

30. Christensen, K.A.; Stenholm, M.; Livbjerg, H. The formation of submicron aerosol particles, $\mathrm{HCl}$ and $\mathrm{SO}_{2}$ in straw-fired boilers Aerosol Sci. 1998, 29, 421-444. [CrossRef]

31. Carvalho, L.; Wopienka, E.; Pointner, C.; Lundgren, J.; Verma, V.K.; Haslinger, W.; Schmidl, C. Performance of a pellet boiler fired with agricultural fuels. Appl. Energy 2013, 104, 286-296. [CrossRef]

32. Werther, J.; Saenger, M.; Hartge, E.U.; Ogada, T.; Siagi, Z. Combustion of agricultural residues. Prog. Energy Combust. Sci. 2000, 26, 1-27. [CrossRef]

33. Sommersacher, P.; Brunner, T.; Obernberger, I. Fuel indexes: A novel method for the evaluationo of relevant combustion properties of new biomass fuels. Energy Fuels 2012, 26, 380-390. [CrossRef]

34. Zeng, T.; Pollex, A.; Weller, N.; Lenz, V.; Nelles, M. Blended biomass pellets as fuel for small scale combustion appliances: Effectof blending on slag formation in the bottom ash and pre-evaluation options. Fuel 2018, 212, 108-116. [CrossRef]

35. Canalís, P.; Sebastian, F.; Arévalo, R.; Quintana, D.; Royo, J. Comparison between the values of predictive indices for sintering and deposition and the experimental results from agropellets combustion tests. In Proceedings of the 27th European Biomass Conference and Exhibition, Lisbom, Portugal, 27 May 2019; pp. 1016-1022.

36. Pronobis, M. Evaluation of the influence of biomass co-combustion on boiler furnace slagging by means of fusibility correlations. Biomass Bioenergy 2005, 28, 375-383. [CrossRef]

37. Munir, S.; Nimmo, W.; Gibbs, B.M. Potential Slagging and Fouling Problems associated with Biomass-Coal blends in Coal-fired Boilers. J. Pak. Inst. Chem. Eng. 2010, 38, 1-11.

38. Rodriguez, J.L.; Álvarez, X.; Valero, E.; Ortiz, L.; de la Torre-Rodríguez, N.; Acuña-Alonso, C. Influence of ashes in the use of forest biomass as source energy. Fuel 2021, 283, 119256. [CrossRef]

39. Fernandez Llorente, M.J.; Carrasco-García, J.E. Comparing methods for predicting the sintering of biomass ash in combustion. Fuel 2005, 84, 1893-1900. [CrossRef]

40. Jeckins, B.M.; Baxter, L.L.; Miles, T.R., Jr.; Miles, T.R. Combustion properties of biomass. Fuel Process. Technol. 1998, 54, 17-46. [CrossRef]

41. Miles, T.R.; Miles, T.R., Jr.; Baxter, L.L.; Bryers, R.W.; Jenkins, B.M.; Oden, L.L. Alkali Deposits Found in Biomass Power Plant: A Preliminary Investigation of Their Extent and Nature; National Renewable Energy Laboratory: Golden, CO, USA, 1995.

42. Xiao, R.; Chen, X.; Wang, F.; Yu, G. The physicochemical properties of different biomass ashes at different ashing temperature. Renew. Energy 2011, 36, 244-249. [CrossRef]

43. Ryu, C.; Yang, Y.B.; Khor, A.; Yates, N.E.; Sarifi, V.N.; Swithenbank, J. Effect of fuel properties on biomass combustion: Part I. Experiments-fuel type, equivalence ratio and particle size. Fuel 2006, 85, 1039-1046. [CrossRef]

44. Royo, J.; Canalís, P.; Quintana, D.; Díaz-Ramírez, M.; Sin, A.; Rezeau, A. Experimental study on the ash behaviour in combustion of pelletized residual agricultural biomass. Fuel 2019, 239, 991-1000. [CrossRef]

45. Díaz-Ramirez, M.; Maraver, D.; Rezeau ARoyo, J.; Sala, S.; Sebastian, F.; Sin, A. Estimation of the deposition on trigeneration system components fueled by ash rich biomass. In Proceedings of the 20th European Biomass Conference and Exhibition, Milan, Italy, 18-22 June 2012; pp. 774-780.

46. Theis, M.; Skrifvars, B.J.; Hupa, M.; Tran, H. Fouling tendency of ash resulting from burning mixtures of biofuels. Part 1: Deposition rates. Fuel 2006, 85, 1125-1130. [CrossRef]

47. Regueiro, A.; Patiño, D.; Granada, E.; Porteiro, J. Experimental study on the fouling behaviour of an underfeed fixed-bed biomass combustor. Appl. Therm. Eng. 2017, 112, 523-533. [CrossRef]

48. Zeng, T.; Weller, N.; Pollex, A.; Lenz, V. Blended biomass pellets as fuel for small scale combustion appliances: Influence on gaseous and total particulate matter emissions and applicability of fuel indices. Fuel 2016, 184, 689-700. [CrossRef]

49. Porteiro, J.; Patiño, D.; Collazo, J.; Granada, E.; Moran, J.; Miguez, J.L. Experimental analysis of the ignition front propagation of several biomass fuels in a fixed-bed combustor. Fuel 2010, 89, 26-35. [CrossRef]

50. Horttanaimen, M.; Saastamoinen, J.; Sarkomaa, P. Operational limits of ignition front propagation against airflow in packed beds of different wood fuels. Energy Fuels 2002, 16, 676-686. [CrossRef]

51. Lindström, E.; Sandström, M.; Boström, D.; Öhman, M. Slagging Characteristics during Combustion of Cereal Grains Rich in Phosphorus. Energy Fuels 2007, 21, 710-717. [CrossRef]

52. Shin, D.; Choi, S. The combustion of simulated waste particles in a fixed bed. Combust. Flame 2000, 121, 167-180. [CrossRef]

53. Royo, J.; Canalís, P.; Zapata, S.; Gómez, M.; Bartolomé, C. Ash Behavior during Combustion of Agropellets Produced by an Agro-Industry-Part 2: Chemical Characterization of Sintering and Deposition. Energies 2022. submitted for publication.

54. Öhman, M.; Boman, C.; Hedman, H.; Nordin, A.; Boström, D. Slagging tendencies of wood pellet ash during combustion in residential pellet burners. Biomass Bioenergy 2004, 27, 585-596. [CrossRef]

55. Wang, L.; Dibdiakova, J. Characterization of ashes from different wood parts of Norway spruce tree. Chem. Eng. Trans. 2014, 37, $37-42$. 
56. García-Maraver, A.; Zamorano, M.; Fernandes, U.; Rabaçal, M.; Costa, M. Relationship between fuel quality and gaseous and particulate matter emissions in a domestic pellet-fired boiler. Fuel 2014, 119, 141-152. [CrossRef]

57. Vassilev, S.V.; Baxter, D.; Vassileva, C.G. An overview of the behaviour of biomass during combustion: Part II. Ash fusion and ash formation mechanisms of biomass types. Fuel 2014, 117, 152-183. [CrossRef] 